San Jose State University

SJSU ScholarWorks

Master's Theses

Master's Theses and Graduate Research

1992

\title{
The role of olfaction in the homing ability of the blue rockfish, Sebastes mystinus in Carmel Bay, California
}

Daniel J. Heilprin

San Jose State University

Follow this and additional works at: https://scholarworks.sjsu.edu/etd_theses

\section{Recommended Citation}

Heilprin, Daniel J., "The role of olfaction in the homing ability of the blue rockfish, Sebastes mystinus in Carmel Bay, California" (1992). Master's Theses. 326.

DOI: https://doi.org/10.31979/etd.9dtg-ebfp

https://scholarworks.sjsu.edu/etd_theses/326

This Thesis is brought to you for free and open access by the Master's Theses and Graduate Research at SJSU ScholarWorks. It has been accepted for inclusion in Master's Theses by an authorized administrator of SJSU ScholarWorks. For more information, please contact scholarworks@sjsu.edu. 


\section{INFORMATION TO USERS}

This manuscript has been reproduced from the microfilm master. UMI films the text directly from the original or copy submitted. Thus, some thesis and dissertation copies are in typewriter face, while others may be from any type of computer printer.

The quality of this reproduction is dependent upon the quality of the copy submitted. Broken or indistinct print, colored or poor quality illustrations and photographs, print bleedthrough, substandard margins, and improper alignment can adversely affect reproduction.

In the unlikely event that the author did not send UMI a complete manuscript and there are missing pages, these will be noted. Also, if unauthorized copyright material had to be removed, a note will indicate the deletion.

Oversize materials (e.g., maps, drawings, charts) are reproduced by sectioning the original, beginning at the upper left-hand corner and continuing from left to right in equal sections with small overlaps. Each original is also photographed in one exposure and is included in reduced form at the back of the book.

Photographs included in the original manuscript have been reproduced xerographically in this copy. Higher quality $6 "$ x 9 " black and white photographic prints are available for any photographs or illustrations appearing in this copy for an additional charge. Contact UMI directly to order.

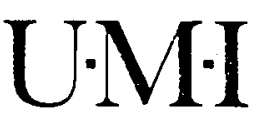

University Microfilms International

A Bell \& Howell Information Company

300 North Zeeb Road. Ann Arbor. MI 48106-1346 USA

$313 / 761.4700 \quad 800: 521-0600$ 
Order Number 1348687

The role of olfaction in the homing ability of the blue rockfish, Sebastes mystinus, in Carmel Bay, California

Heilprin, Daniel Joseph, M.S.

San Jose State University, 1992 
- 
THE ROLE OF OLFACTION IN THE HOMING ABILITY OF THE BLUE ROCKFISH, SEBASTES MYSTINUS

IN CARMEL BAY, CALIFORNIA

\author{
A Thesis \\ presented to \\ the Faculty of the Department of Biology at \\ Moss Landing Marine Laboratories \\ and \\ San Jose State University
}

\begin{abstract}
In Partial Fulfillment
of the Requirements for the Degree

Master of Science in Marine Science
\end{abstract}

by

Daniel J. Heilprin

May, 1992 
APPROVED FOR THE DEPARTMENT OF BIOLOGY

Hepolm Paulder

Dr. Gregor M. Cailliet, Moss Landing Marine Laboratories
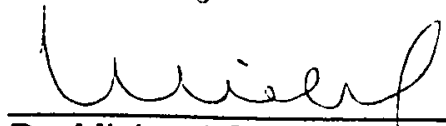

1(

Dr. MichaelSS. Foster, Moss Landing Marine Laboratories

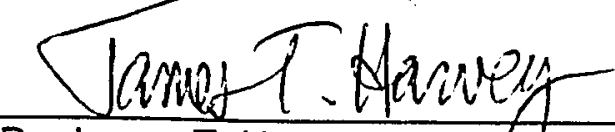

Dr. James T. Harvey, Moss Lahding Marine Laboratories

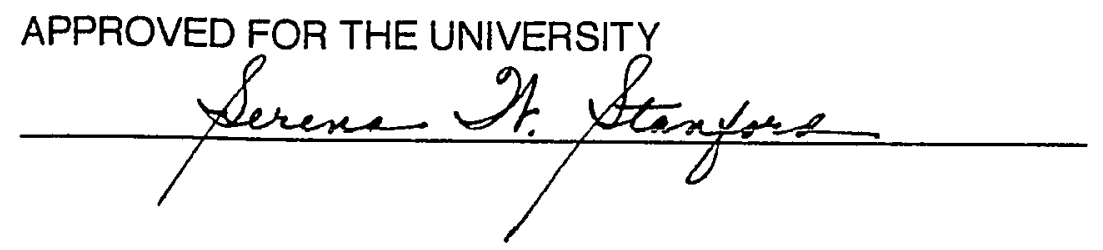




\begin{abstract}
THE ROLE OF OLFACTION IN THE HOMING ABILITY

OF THE BLUE ROCKFISH, SEBASTES MYSTINUS

IN CARMEL BAY, CALIFORNIA
\end{abstract}

By

Daniel J. Heilprin

The role of olfaction in homing behavior of blue rockfish, Sebastes mystinus, was investigated in Stillwater Cove, Carmel Bay, California. In fall 1990 and spring 1991, 200 normal and 200 olfactory-impaired (anosmic) fish were tagged and released at four sites $(0,1,2.6$, and $4.4 \mathrm{~km}$ from Stillwater Cove). Fourteen of 100 normal and 4 of 100 anosmic fish displaced $1.2 \mathrm{~km}$ returned to the location where they were caught. Only one anosmic fish displaced $2.6 \mathrm{~km}$ and two normal fish displaced $4.4 \mathrm{~km}$ returned to their capture site. Tagged fish were never resighted at any reef except the location of capture or release indicating movement between reefs did not occur and home-site fidelity in this species. Moreover, all tagged individuals were resighted within $20-25 \mathrm{~m}$ of their capture location suggesting blue rockfish have small home ranges. Nine of 50 fish displaced $1.2 \mathrm{~km}$ returned to their home site in fall, while 9 of 150 displaced the same distance returned in spring suggesting a seasonal component to homing. Both normal $(n=14)$ and anosmic fish $(n=4)$ were able to return to the capture site, however, normal fish were significantly more successful (Chisquare, $P<0.05)$. These results indicated olfaction was at least one factor influencing homing success in blue rockfish. 


\section{ACKNOWLEDGEMENTS}

I would like to begin by thanking my parents and grandparents for both emotional and financial support throughout my education. I would like to thank Christine Low for her endless friendship, support, and love. I am deeply indebted to Dr. Gregor Cailliet for providing me with insight, guidance, and incentive to learn all I could about fishes and ecology. I would like to thank my other committee members, Drs. Michael Foster and James Harvey for their countless suggestions during this project. I would also like to thank Dr. James Barry, John Heine, Mary Nishimoto, Guillermo Moreno, Mark Carr, Don Canestro, and Rocky Strong for their friendship and input during all stages of this study. I am grateful to Mary Yoklavich for her review and suggestions regarding many aspects of this study. Sheila Baldridge and Sandi O'Neil provided invaluable library research assistance. Gail Johnston, Sandy Yarbrough and Irene Chung proved instrumental in getting me through all of SJSU's red tape. Weather data were provided by Dr. William Broenkow.

I would like to thank the numerous people who have contributed greatly to the field study. These included G. Leonard, S. Osborn, G. Moreno, M. Burd, T. Okey, M. McNulty, D. Steller, F. Roddy, T. Bennett, K. Scott, C. Roberts, and R. Clark. I would also like to thank the people who were invaluable to me in the laboratory including M. Nishimoto, M. Hester, C. Bretz, M. McNulty, H. McNulty, G. Leonard, N. Crane, L. Lewis.

I greatly appreciate the use of the seawater facilities provided by Hopkins Marine Station (John Kono) and California Fish and Game's State Mariculture Laboratory at Granite Canyon, CA (Dr. R. Lea). I would like to thank G. Van

Dykhuizen, J. O'Sullivan, and C. Harrold at Monterey Bay Aquarium for all their 
technical support. Additionally, I would like to acknowledge the Pebble Beach Country Club and their Staff for allowing access to Stillwater Cove.

This project would not have been possible without financial support from The David and Lucille Packard Foundation, The Earl and Ethel Myers Marine Biology and Oceanographic Trust, and The American Museum of Natural History's Lerner-Grey Marine Research Fund. 
TABLE OF CONTENTS

PAGE

\author{
ABSTRACT \\ ACKNOWLEDGEMENTS \\ LIST OF TABLES \\ LIST OF FIGURES \\ INTRODUCTION \\ MATERIALS AND METHODS \\ STUDY SITE \\ HOME SITE ASSESSMENT \\ HOMING ASSESSMENT \\ OLFACTORY IMPAIRMENT \\ DISPLACEMENTS
}

iii

iv

vii

viii

1

6

6

6

7

7

8

RESULTS

11

HOME SITE ASSESSMENT

HOMING ASSESSMENT

ROLE OF OLFACTION 13

DISCUSSSION

16

HOME SITE ASSESSMENT $\quad 16$

HOMING ASSESSMENT 18

ROLE OF OLFACTION

LITERATURE CITED 31

TABLES 36

FIGURES $\quad 40$ 


\section{LIST OF TABLES}

PAGE

1. Total number of fish which homed and were 36 resighted at all displacement sites during both seasons.

2. Number of normal and anosmic fish (by sex) which were collected and later released during both seasons.

3. Chi-square analysis of homing and the number

38 of normal and anosmic fish resighted during each season.

4. Number and percent effort for resighting surveys 39 at each release site during each season. 


\section{LIST OF FIGURES}

\section{PAGE}

1. Location of the study sites in Carmel Bay, California.

2. Head of a hypothetical bony fish indicating location of nares and nasal rosettes.

3. The relationship between distance displaced and the number of days until an individual was resighted.

4. Size frequency distribution for fish captured, tagged, and later released during both seasons.

5. The relationship between size of fish and the number of days before resighting for both displaced and transplant control fish.

6. Relationship between sex and resighting of fish displaced 1.2 to $4.4 \mathrm{~km}$ from their home site.

7. Relationship between sex and resighting of transplant control fish.

8. Relationship between the number of normal and anosmic fish homed 1.2 to $4.4 \mathrm{~km}$ and the number of days until they were resighted.

9. Relationship between the number of normal and anosmic fish resighted at the home site and the number of days until they were resighted.

10a. Map of the surface area of giant kelp, Macrocystis pyrifera, during April in 1989.

10b. Map of the surface area of giant kelp, Macrocystis pyrifera, during August in 1990.

10c. Map of the surface area of giant kelp, Macrocystis pyrifera, during April in 1991. 


\section{INTRODUCTION}

Migration, movement patterns, and homing can permit fish to escape from unfavorable conditions and to exploit habitats created by successional, seasonal, and daily changes in the environment (Dingle, 1985). Researchers of these phenomena have described the paths, timing, duration, speed, precision of fish movements, and the identification of orientation cues and their mode of detection (e.g. olfactory, celestial, and electromagnetic senses; see reviews by Harden Jones, 1968; Leggett, 1977; Northcote, 1978; McCleave et al., 1984; and Leggett, 1985).

The blue rockfish, Sebastes mystinus, is found commonly in kelp forests from Pt. Santo Tomas, Baja California, to at least Vancouver Island (Miller and Lea 1972; Love 1991). Blue rockfish are one of the few schooling rockfishes distributed in midwater, over shallow and deep reefs, and in kelp forests (Eschmeyer et al., 1983). Abundances of this species over their entire range are highly variable, with numbers reaching their greatest levels in summer and fall and declining in winter and spring. Little information exists concerning movement patterns and homing in this species.

Members of the genus Sebastes are generally long-lived, and much information is available regarding growth and reproduction of some species. Growth rates for many species, including blue rockfish are low, with males and females growing at equal rates. Blue rockfish reach reproductive maturity at approximately $31 \mathrm{~cm}$ (standard length) or 5-6 years of age (Love, 1991). Spawning occurs between November and March, with a peak in January or February. Beginning in April, juvenile blue rockfish recruit to kelp forests in central and northern California, often becoming the most abundant species of 
rockfish and a substantial food source for many fishes, birds, and marine mammals (Hallacher and Roberts, 1985; Love, 1991). Additionally, Bodkin (1986) and Miller and Geibel (1973) suggested both adult and juvenile blue rockfish comprise the greatest fish biomass in kelp forest communities in central and northern California.

Because rockfishes can be found in high numbers in habitats which are easily accessible to small boats, this genus has historically been a major part of California's party and private vessel sport catch from Los Angeles County northward. In 1985, rockfishes comprised $33 \%$ of all recreational fish landed in the state, with blue, black (Sebastes melanops), and yellowtail (S. flavidus) rockfish comprising $30 \%$ of this total (Lenarz, 1986). Blue rockfish are taken by divers and occasionally hooked by pier and jetty fishermen, particularly in central and northern California (Love, 1991). Most, however, are caught by recreational fishermen.

This species has been over-harvested in many areas because fishing effort has concentrated on shallow reefs and in kelp forests where limited movement of blue rockfish occurs (Love, 1991). Successful management programs designed to avoid overexploitation of rockfishes on specific reef systems depend on information regarding habitat use and seasonal patterns of movement. Due to their tendency to school, blue rockfish north of $\mathrm{Pt}$. Conception are often found with other recreationally exploited schooling fish such as olive rockfish, Sebastes serranoides and black rockfish, S. melanops, while they mix with kelp bass, Paralabrax clathratus; olive rockfish, blacksmith, Chromis punctipinnis, and halfmoons, Girella nigricans south of Pt. Conception. Adult blue rockfish reside for extended periods on shallow reefs, but tend to 
wander more on deeper reefs (Love, 1991).

Nearshore coastal fishes experience major seasonal changes in their environment, which can influence their feeding behavior, reproductive behavior, and movement patterns. Changes in food and habitat availability, caused by environmental disturbances such as the El Niño, can produce adverse conditions for blue rockfish. Lower zooplankton abundances, as well as loss of kelp forest habitat from the 1983 El Niño event caused extreme waves and redistribution of fish to other habitats. Stress associated with this anomalously warm water reduced the abundance of prey for many planktivorous fishes, thus leading to changes in habitat quality (Lenarz and Echeverria, 1986; Bodkin et al., 1987). The poorest habitat conditions for blue rockfish occur during fall and winter when swells from winter storms remove large amounts of giant kelp, Macrocystis pyrifera, a major source of habitat structure in many temperate marine reefs. Blue rockfish feed primarily on large, gelatinous zooplankton such as thaliaceans, ctenophores, and pelagic hydrozoans, whose availability as a food source varies seasonally (Hobson and Chess, 1988). Optimum feeding conditions for blue rockfish in northern California occur during spring and summer, when increased nutrients from strong upwelling and increased daylight result in growth of diatom populations that constitute the food-base of zooplankton (Hobson and Chess, 1988).

If blue rockfish movement patterns are affected by disturbances, such as winter storm removal of kelp and changes in optimum feeding conditions (both of which influence habitat quality), seasonal variation in homing performance may occur. Experimental removal of kelp canopy yielded dramatic declines in a number of juvenile rockfish species, with blue rockfish exhibiting the largest 
decrease (Bodkin, 1988). I have observed decreases in blue rockfish numbers in a central California kelp forest during winter storms when large portions of kelp are removed.

There is some disagreement concerning the definition of homing. For this study, homing is defined as : "the return of a fish after migratory, accidental, or experimental displacement to a place formerly occupied instead of going to other equally probable places" (Gerking, 1959). Equally probable places refer to areas occupied by other individuals of the same species.

Although there is little information on movement patterns, home site fidelity, or homing behavior in blue rockfish, homing has been previously demonstrated in several species of rockfishes: black and yellow, Sebastes chrysomelas (Hallacher, 1984); white-sided, S. taczanowski (Markevich, 1988); yellowtail, S. flavidus (Carlson and Haight, 1972); and brown rockfishes, S. auriculatus (W. Lenarz, NMFS, Tiburon, CA., pers. comm.). Studies addressing movement patterns and homing may provide valuable information on habitat preferences and habitat use (Matthews, 1990a). Homing may benefit fishes in a number of ways. Homing may allow some fishes to return to natal areas (trout and salmon) and could be beneficiai in returning to specific habitats higher in quality then previously occupied areas. Homing may also allow individuals to return to their home sites after foraging in different areas. If changes in environmental conditions affect habitat quality, such as kelp canopy persistence, then changes in homing performance and abilities may also change.

Chemoreception may be important for successful migration and movement in a number of fishes. According to Hara and Zielinski (1989), fishes 
detect chemical cues through two major chemosensory channels, olfaction (smell) and gustation (taste). Olfaction has been shown to be an important sensory mechanism used for homing and migrations by a diverse array of fishes such as chinook salmon, Oncorhynchus tshawytscha (Groves et al., 1967; Hara, 1970), longear sunfish, Lepomis megalotis megalotis (Gunning, 1959), and tidepool sculpin, Oligocottus maculosus (Khoo, 1974). The sensory mechanisms used by rockfishes in homing, however, have never been investigated. The only olfactory work done on rockfishes is a description of the olfactory apparatus in black rockfish, Sebastes melanops, by Brown (1962).

Tagging studies of sensory-impaired fishes can give direct information about involvement of particular sense organs in homing, allowing researchers to investigate alternate senses which may or may not play a role in homing ability (Stasko, 1971). Sensory mechanisms such as geomagnetic detection by Ampullae of Lorenzini or presence of magnitite and visual sun-compass orientation have been suggested to guide the return of a number of fishes to a home site. After an initial orientation phase, presumably using the earth's magnetic field, juvenile lemon sharks, Negaprion brevirostris, in Bimini lagoon, Bahamas, were able to return home from distances of up to $3 \mathrm{~km}$ offshore (W.R. Strong, U.C. Santa Barbara, Santa Barbara, CA., unpubl. data). Also, visual cues may assist homing of intertidal sculpin, although it may be less important than olfaction (Hara, 1970; Khoo, 1974)

The objectives of this study were to: (1) determine if blue rockfish have home sites by assessing home-site fidelity, home ranges, and movement patterns; (2) assess the relationship of homing ability to distance displaced, season, size, and sex; and (3) assess the role of olfaction in homing. 


\section{MATERIALS AND METHODS}

\section{Study Site}

This study was done in Stillwater Cove, Carmel Bay, California (36034'N, $121^{0} 56^{\prime} \mathrm{W}$, Fig. 1). The cove opens to the south and is protected from large northerly swells associated with winter storms and strong northwesterly winds occurring in spring. During summer and fall, a dense canopy of giant kelp, Macrocystis pyrifera may fill the cove, but is usually thinned by winter storms (Reed and Foster, 1984). Large aggregations of adult and juvenile blue rockfish are distributed throughout kelp forests during summer and fall, utilizing the canopy as a structural refuge.

\section{Home Site Assessment}

Tagged fish were used to assess home site fidelity and movement patterns of blue rockfish between three different sites within Stillwater Cove. Tagging was done between February and April in 1989 at Wash Rock, Pescadero Rocks, and Arrowhead Point (Fig. 1). For this part of the study, blue rockfish were captured by divers using hook-and-line techniques at depths of 5 to $10 \mathrm{~m}$. Each fish was tagged at depth immediately after capture with a Floy FD-67 vinyl anchor tag, inserted into the dorsal musculature. Tags were colorcoded so that fish from each reef could be distinguished. Standard lengths and sex were not recorded. Home site fidelity, home ranges, and movement patterns between and away from reefs were assessed by noting the location of fish relative to their tagging location during subsequent SCUBA surveys. Fish were surveyed using random techniques within and outside of Stillwater Cove to determine movement patterns. 


\section{Homing Assessment}

Fish were tagged between September and October (fall) in 1990 and in April (spring) 1991 to address homing ability in this species. For this part of the

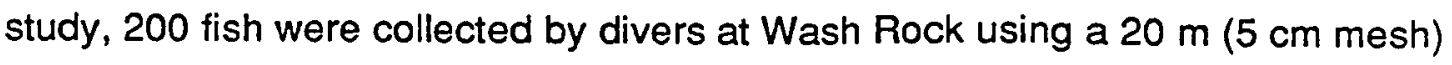
monofilament gill net. Groups of 15 to 20 fish were carefully removed from the gill net, placed in plastic-lined canvas goody bags, and slowly brought to the surface. Fish were placed in aerated Rubbermaid $68 \mathrm{~L}$ storage containers filled with seawater for transport to the laboratory. All fish were placed in two $1000 \mathrm{~L}$ fiberglass holding tanks at Hopkins Marine Station, Pacific Grove, California, for a period of 4 to 5 days before release. Each fish was tagged with a numbered and color-coded Petersen disc tag (Floy Tagging Co., Seattle, WA.), held in place with a $10 \mathrm{~cm}$ nylon cable tie. Tags were placed in the dorsai musculature just behind the first dorsal fin with a brass cannula. Standard length in $\mathrm{mm}$ and sex (determined by presence of urogenital papillae in males) were recorded.

\section{Role of Olfaction}

Olfactory-impairment (Anosmia)

One hundred olfactory-impaired (anosmic) fish were used in this part of the study to test whether olfaction plays a role in blue rockfish homing. Methods used to impair olfaction in fishes have included cutting the olfactory nerves, cauterizing the olfactory rosettes, or plugging the nares with vaseline, waxes, latex, or cotton (Stasko, 1971). Olfactory stimuli are received by the nasal rosettes, located within the olfactory chamber (Fig. 2). To eliminate this sensory organ, the skin between the two nares was cut in order to expose the nasal rosette (Fig. 2). The entire rosette was cauterized using a Realistic $₫$ butanepowered soldering gun (1 $\mathrm{mm}$ tip). The entire procedure took place out of water 
and lasted approximately 2 minutes per fish. Fish were returned to holding tanks immediately after tagging and olfactory impairment. Fish were treated for scale loss and infection during this part of the study with the fungicide Nitrofurazone (dosage 10-15 ppm) for a period of 4-5 days following impairment and handling. This short period in captivity allowed an assessment of mortality due to these procedures.

\section{Displacements}

Fish were transported by skiff to release sites in aerated containers of seawater. To prevent the possibility that anosmic fish might follow normal fish returning to their home site, individuals were released at the surface and from opposite sides of the boat. Anosmic fish were released first at approximately 510 second intervals. Ten fish (five normal and five anosmic) were released weekly at Arrowhead Point, Lone Cypress, and Bluefish Cove in Point Lobos State Park, $1.2 \mathrm{~km}$ east, $2.6 \mathrm{~km}$ north, and $4.4 \mathrm{~km}$ south of Wash Rock, respectively. Ten fish (five normal and five anosmic) were also released weekly at Wash Rock (transplant controls).

Surveys were conducted weekly using SCUBA for two months following displacement of 200 fish each period. Surveys consisted of two divers locating large schools of blue rockfish at each release site. Divers inspected schools for approximately 10-15 minutes. After searching the aggregations, divers looking for tagged fish would swim approximately $100-150 \mathrm{~m}$ east, along edge of the kelp. The return search (100-150 m west) was done 10-15 m within the kelp bed.

Sites within and outside the cove (determined by presence of blue 
rockfish aggregations) were surveyed for two months each season after a total of 200 fish were released. Between April and June in 1991 an estimate of relative abundance of blue rockfish along a $100 \mathrm{~m}$ transect was derived by counting the number of fish in a imaginary $3 \mathrm{~m} \times 3 \mathrm{~m}$ box during each resighting survey. Additionally, vertical transects were done to assess the vertical distribution of blue rockfish during varying environmental conditions such as increased swell and wave action. During resighting surveys, individual fish were identifiable at distances of 1-3 m; however, accurate visual identification of individual fish became impossible due to tag fowling approximately 3-4 weeks after displacement. Therefore, fish with fowled tags were sacrificed to obtain data on homing.

Due to a low number of returns from Lone Cypress and Bluefish Cove (during fall) these sites were eliminated from the April 1991 releases. From 3 April to 13 April in 1991, fish were collected daily from Wash Rock until a total of 200 was reached. After collection, fish were placed in two $1000 \mathrm{~L}$ fiberglass tanks at California Department of Fish and Game's State Mariculture Lab at Granite Canyon, CA. During this part of the study, all tagging and impairment procedures were the same as above, with the exception that $2 \%$ Nitrofurazone ointment was placed in the nasal passages of all anosmic fish $(n=100)$. Additionally, normal fish $(n=100)$ were burned on the outside of their snout to simulate the impairment procedure. Fish were released using the same procedures as above; however, fish during this part of the study were only released to Arrowhead Point and Wash Rock.

Because tests to determine the effectiveness of anosmia are lacking in most sensory-impairment field studies, the nasal rosette of anosmic fish were 
examined in the laboratory. Therefore, twenty fish were collected on 14 April in 1991 to determine rate of tag loss, mortality due to anosmia, and possible rosette regeneration in the laboratory. Ten anosmic and ten normal fish were placed in a $1000 \mathrm{~L}$ fiberglass tank, and fed chopped squid, 2-3 times a week, for 75 days. Observations of feeding behavior were made daily for normal and anosmic fish. After 75 days, anosmic fish were sacrificed to examine nasal rosettes and test for effectiveness of surgical procedures. Rosette tissue was examined microscopically to determine completeness of anosmia and degree of regeneration.

All factors which possibly could influence homing performance (season, sex, size, and olfactory senses) during both seasons were tested using chisquare analyses (Zar, 1984). Also, differences between the mean sizes of fish collected and season were tested with an unpaired two sample T-test. 


\section{RESULTS}

\section{Home Site Assessment}

Resighting of fish tagged and released in February through April, 1989 gave an indication of movement patterns and home site fidelity in this species. No tagged individuals were seen at any location other than their site of capture and release during 23 SCUBA surveys conducted at Wash Rock $(n=7)$, Arrowhead Point ( $n=9)$, and Pescadero Rocks $(n=7)$ between February and April in 1989. Additionally, tagged individuals were not seen during eight surveys conducted at random locations within Stillwater Cove, suggesting movement between reefs did not occur. Multiple resightings of the same individual in the same location over time (four fish tagged in spring 1989 were resighted 2-3 times at Wash Rock over the next year) indicated this species remained near particular sites. Moreover, tagged fish were never resighted more than 20-25 $\mathrm{m}$ from their capture and tagging location (home site), suggesting blue rockfish occupy small home ranges.

\section{Homing Assessment}

A preliminary indication of homing ability of this species was given by the movement of 16 fish collected at Wash Rock and displaced to Arrowhead Point and Pescadero Rocks (1.2 and $0.80 \mathrm{~km}$, respectively) during spring 1989. Four of eight fish from Arrowhead Point and three of eight fish displaced to Pescadero Rocks homed within six days (only one survey conducted).

Of the 300 fish displaced from their home site during fall 1990 and spring 1991 , the total number that homed from various release sites ranged from 1-9 (Table 1). Homing occurred in 12 of 150 fish displaced between $1.2-4.4 \mathrm{~km}$ 
during fall in 1990, and 9 of 150 fish displaced only $1.2 \mathrm{~km}$ during spring in 1991. Homing was observed in eight normal and four anosmic fish during fall 1990 and eight normal and one anosmic fish in spring 1991.

Resighting of tagged individuals was highly variable throughout the study. At Wash Rock, fish captured and released at the capture site (transplant controls) were resighted between 0-297 days after release during both fall and spring (Fig. 3). Fish displaced $1.2 \mathrm{~km}$ were resighted between 0-324 days, whereas one fish returning from Lone Cypress $(2.6 \mathrm{~km})$ homed after 7 days. The two fish which homed from Bluefish Cove $(4.4 \mathrm{~km})$ were resighted after 121 and 297 days. There was no significant correlation $\left(r^{2}=0.256\right)$ between distance displaced and number of days until an individual fish was resighted at the home site. However, fish homing from Arrowhead Point generally returned in the shortest time, usually within one hour.

Seasonal comparisons in homing performance revealed a difference between the proportion of individual fish which homed from Arrowhead Point in spring versus fall. In spring 1989 four of eight fish released at Arrowhead Point homed (Table 1). In fall 1990, nine of 50 fish released at the same location returned to their home site, while nine of 150 homed the same distance in spring 1991.

Because homing performance may be affected by size (age) of the fish, the relationship between size (standard length in $\mathrm{mm}$ ), and number of days before resighting was examined. The mean size of fish collected in fall 1990 were significantly smaller than in spring 1991 (T-test; $P=0.0133 ;$ Fig.4). Resightings also indicated most size classes were able to home (Fig. 5). The smallest individuals released $(150-200 \mathrm{~mm})$ were resighted within the first 40 
days, while resighting of medium and larger fishes varied. However, three transplant control fish, of medium and large size were resighted 292 to 300 days after release, while two of the largest fish displaced were resighted after 292 and 324 days. This suggests no relationship exists between homing success and size or age of adult blue rockfish used in this study.

To control for possible differences in homing performance between male and female fishes, similar numbers of both sexes (normal and anosmic) were released during both seasons (Table 2). For fish displaced between 1.2 and $4.4 \mathrm{~km}$, seven males and 11 females were resighted within 40 days, and no males were resighted after 40 days (Fig. 6). Additionally, one female was recaptured by a diver after the sampling period had ended. The use of transplant controls allowed me to assess whether there was a relationship between resighting capability and sex. During all surveys at Wash Rock, males were resighted more than females within 40 days of being released (Fig. 7). After 40 days, however, both sexes were resighted.

\section{Role of Olfaction Assessment}

During all surveys, 13 normal and four anosmic fish were resighted within 40 days of being displaced $1.2-4.4 \mathrm{~km}$ (Fig. 8). Similar numbers of anosmic and normal fish were resighted after 40 days, although the sample size was extremely low. Transplant controls were used to test whether normal and anosmic fish were resighted equally (Fig. 9). Results from surveys at their home site indicated no differences existed between normal and anosmic fish resightings over the course of the study.

Although sample sizes were low, chi-square analyses indicated more 
normal than anosmic fish homed after being displaced $1.2 \mathrm{~km}(P<0.05)$ in spring 1991, but not in fall (Table 3). For both seasons pooled, more normal than anosmic fish homed from Arrowhead Point $(P<0.05)$. There were no significant differences $(P<0.05)$ in number of normal and anosmic transplant controls resighted at their home site in either season. Survey effort (Table 4) was different at each release site, with effort being greatest at the home site.

The relative abundance of blue rockfish within a $9000 \mathrm{~m}^{2}$ area at Wash Rock from April to June in 1991 was determined to address turnover rate at the home site and to estimate the likelihood of resighting a tagged fish. Abundance estimates during 12 surveys ranged from 75 to 3000 fish per $9000 \mathrm{~m}^{2}$ $(\bar{X}=1169 \pm 933 \mathrm{SD})$. Also, the number of tagged fish resighted at each study site per survey varied, ranging from $0-5$, with usually $1-2$ fish resighted each survey. Surveys conducted during spring 1989, fall 1990, and spring 1991 (Table 4) indicated resighting effort was different at all release sites.

Microscopic examination of anosmic fish in the laboratory revealed no rosette regeneration occurred in fish after one year $(n=2)$, and no rosette regeneration was detected in any of the ten fish held in the laboratory for 75 days. Impairment was also complete in fishes from the laboratory experiment $(n=10)$. Observations taken 2-3 times per week for 75 days revealed no tag loss or mortality occurred from impairment or handling procedures. Moreover, no differences were observed in feeding behavior between captive normal and anosmic fish, suggesting that the impairment procedure did not alter feeding behavior of blue rockfish in the laboratory. Surveys at Wash Rock (home site) indicated fish resumed normal behavioral patterns following release. Fish were never observed going into rocks or ledges immediately after release. I 
observed tagged fish orient themselves spatially and directionally, search the area briefly, possibly for conspecifics, and then begin to move towards the home site following release. Transplant controls released at their home site were observed displaying the same behavior, often brushing up against other blue rockfish contacted.

Data obtained on weather conditions (available from W. Broenkow, Moss Landing Marine Labs) and surface area of kelp canopy from digitized infrared aerial photographs (C. Harrold, Monterey Bay Aquarium) showed seasonal variations (Figs. 10a-c) that may have influenced the resighting of fish and possibly homing ability. In April 1989 when the preliminary work for this study was done, the kelp canopy was thick and full, mainly due to the low number of winter storms (Fig. 10a). Kelp canopy was at maximum density in August 1990, following a spring-summer period of low storm activity (Fig. 10b). However, between February and April 1991, winter storms frequently removed large sections of kelp canopy throughout the entire cove (Fig. 10 C). This periodic thinning may eliminate visual cues used by fish returning from release sites.

Because the weather data obtained were for Monterey Bay, a northfacing inlet, and not Stillwater Cove in Carmel Bay, a south-facing cove, only generalities could be drawn concerning weather. A general trend existed between high wind, increased wave height and swell, and the amount of destruction or damage ocurring on kelp canopy. During periods of increased wave heighth and swell, schools of blue rockfish were highly dispersed and resided under rocks and ledges at deeper depths. Moreover, unstable conditions decreased visibility in the water column. This factor influenced diver's ability to resight tagged fish and biased the abundance estimates. 


\section{DISCUSSION}

\section{Home Site Assessment}

Because movement patterns are important in determining management strategies for exploited fisheries, a number of studies have focused on movement and homing in the genus Sebastes and homing ability has been found to be common. Black rockfish, S. melanops, exhibited no significant movement away from their home site, but may actively seek out prey over large distances (Culver, 1986). Kelp rockfish, S. atrovirens, were seldom observed more than $6.5 \mathrm{~m}$ from their home site by Van Dykhuizen (1983), suggesting small home ranges that could make this species susceptible to overexploitation. Miller et al. (1967) described blue rockfish as non-migratory, displaying movement of less than $1-2 \mathrm{~km}$.

I found tagged fish remained at reefs where they were released and were commonly resighted within $20-25 \mathrm{~m}$ of the capture site. Due to the lack of observed movement between reefs, I suggest that blue rockfish occupy small home ranges and possess great home-site fidelity. Such fidelity was demonstrated by high recapture rate at reefs occupied by conspecifics of the yellowtail rockfish, S. flavidus (Carlson and Haight, 1972). Copper and quillback rockfishes, $S$. caurinus and $S$. maliger make exploratory excursions which enable them to examine habitat suitability at other locations and return to previously occupied habitats (Matthews, 1990b). In this study, fifteen blue rockfish were resighted more than once and usually a number of weeks or even months after initial resighting. 
I suggest blue rockfish may occupy a specific reef system during the spring and summer and move to different areas during fall and winter. Four blue rockfish released in spring 1989 returned to and were resighted at Wash Rock (their initial release site) in summer, over one year later. This suggests blue rockfish occupying Wash Rock during calm periods (summer) may move offshore during unstable periods (winter and spring) to deeper more protected reefs.

Blue rockfish may occupy certain reefs during summer and fall because the density of their spatial refuge, Macrocystis pyrifera, is at its highest levels and environmental conditions are stable. However, when conditions become unsuitable (i.e. winter storms) and large areas of kelp forest are removed, fish may relocate to deeper offshore reefs. Due to biased surveys (Table 4), no direct evidence exists for their offshore movement. During 32 surveys conducted in Fall 1990 and 39 in Spring 1991, tagged individuals were only resighted when weather conditions were favorable. My survey results are also biased because no surveys were conducted during the night or at times when storms persisted. Also Matthews (1986) suggested that black and yellow rockfish, Sebastes chrysomelas and gopher rockfish, S. carnatus were not resighted during winter months because fish vacated home reefs. In this study, surveys during more unstable times revealed blue rockfish fish were highly dispersed and moved to deeper depths $(>30 \mathrm{~m})$ at their home site. Fish may also have moved offshore or possibly away from their home sites.

Blue rockfish abundances were strongly affected by season. Fish abundances were lower in winter and spring at all exposed sites such as Arrowhead Point. At Wash Rock, the number of fish fluctuated during the winter, 
but returned to high levels in summer and fall. Matthews (1990b) found rockfishes only inhabited low relief reefs in summer coincident with peak algal cover. Other explanations for the variability in resightability may be that SCUBA surveys were not adequate. Tagged fish may have been at other locations on the reef where divers could not see them, or actively avoided divers. Tagged individuals often had to be chased into ledges and to deeper reefs in order to identify them.

\section{Homing Assessment}

Information regarding homing and movement patterns is essential for proper management of commercially and recreationally significant species of rockfishes, including blue rockfish. Salmonid fishes are famous for returning to natal streams after years of oceanic feeding (Quinn, 1990). A wide variety of freshwater and anadromous fishes also possess homing abilities, including muskellunge, Esox masquinongy (Miller and Menzel, 1986); Atlantic herring, Clupea harengus (Wheeler and Winters, 1984); and the roach, Rutilus rutilus (L'Abee-Lund and Vøllestad, 1985). Many new studies are indicating more species of fishes including members of the family Scorpaenidae possess homing abilities.

Homing in the genus Sebastes is widespread. Carlson and Haight (1972) reported yellowtail rockfish, S. flavidus returned from distances of up to $22.5 \mathrm{~km}$, and fish held in the lab for 3 months also returned in high numbers, indicating a lasting memory of their home site. Hallacher (1984) found black and yellow rockfish, S. chrysomelas homed after displacement of up to $50 \mathrm{~m}$, but none were found returning from $1.5 \mathrm{~km}$. Eastern seaperch, Sebastes 
taczanowski, homed from $0.5 \mathrm{~km}$, and homing performance decreased at distances of 1.0 and $3.0 \mathrm{~km}$ (Markevich, 1988). Additionally, displaced brown rockfish, S. auriculatus, have homed from distances of $25 \mathrm{~km}$ in San Francisco Bay (W. Lenarz, NMFS Tiburon, CA., pers. comm.). In the present study, blue rockfish were able to home from distances of up to $4.4 \mathrm{~km}$, with homing performance inversely related to distance displaced (Fig. 3). Visual observations of fish released at Arrowhead Point indicated movement toward the home site occurred immediately after release.

I suggest seasonal changes in the environment may dramatically affect homing performance in the blue rockfish. Khoo (1974) found no significant differences in homing performance between seasons for the wooly sculpin, Oligocottus maculosus. However, in this study, I found that homing success from Arrowhead Point was highly variable. In spring 1989, fall 1990, and spring 1991 homing percentages were 50,18 , and $6 \%$, respectively. During spring 1989, kelp canopy can be classified as moderate (Fig. 10a), while kelp canopy cover during fall 1990 was high (Fig. 10b) and low in spring 1991 (Fig. 10C). The relationship between kelp canopy and homing success is difficult to interpret. I suggest that when kelp canopy is moderate to high, blue rockfish home more successfully. This may be due to the use of vision and visual cues (kelp canopy) or other senses, as well as olfaction.

Because cues associated with home site recognition may be learned at certain ages, younger (and presumably smaller) fish may not home as well as older, larger fishes. However, there was no relationship was found between resightability or homing performance and size of any fish (Fig. 5). Craik (1981) found smaller size classes $(2-3 \mathrm{~cm})$ of intertidal sculpin, Oligocottus maculosus, 
did not home. Similar results were obtained by Green (1973) for mosshead sculpin, Clinocottus globiceps. The percentage of Ol. maculosus that successfully homed increased with length, peaking between 5 and $7 \mathrm{~cm}$ total length (age 2), with considerable variability in smaller size classes (Craik, 1981). Juvenile fish moved extensively between tidepools and began establishing home sites and homing behavior at about $3 \mathrm{~cm}$. During this period of extensive movement, home sites were presumably learned (Craik, 1981). I tagged only adult fish (>200 $\mathrm{mm} \mathrm{SL}$ ), estimated by Miller et al. (1967) to be 3-10 years of age. Sub-adult blue rockfish ( $<200 \mathrm{~mm} \mathrm{SL}$ ) homed from $1.2 \mathrm{~km}$, but with less success than larger fish (G. Leonard, Moss Landing Marine Labs, Moss Landing, CA., pers. comm.). Juvenile blue rockfish may make exploratory excursions, but only after a home site is established. These periodic journeys may be to search for more suitable habitat, previously occupied areas, or places with lower incidence of predation.

Other factors may influence resighting blue rockfish of different sizes. For example, I found that larger individuals may be harder to resight because they tend to reside in rocks and crevices at deeper depths more often than smaller fish. Larger fish may also distribute themselves lower in the water column or aggregation than smaller fishes.

Although growth rates between male and female blue rockfish do not differ (Miller et al., 1967), differences in homing success between sexes may exist. While Williams (1957) found that homing behavior of wooly sculpin, Clinocottus analis, was not size-dependent, results indicated young males tended to stray more than females. However, McCleave (1967) and LaBar (1971) found no significant differences in homing performance between male 
and female cutthroat trout. I found differences in homing performance to exist between male and female blue rockfish (Fig. 6). These differences may be due to a lessened drive to home by males, or males may only home during certain times of the year. Also, homing instinct for female blue rockfish may increase during reproductively active periods. Female roach, Rutilus rutilus, had lower recapture rates than males, which L'Abee-Lund and Vøllestad (1985) suggested were caused by increased mortality induced by marking and handling procedures. This stress may disturb the natural spawning behavior in females, causing severe physiological stress and increased mortality.

Although difficult to assess, reduced homing success may have be directly related to stress associated with capture and handling techniques. Disturbance during capture and tagging did not affect homing behavior or fidelity of $O$. maculosus to the home pool (Green, 1971). However, copper and quillback rockfish remained in the release site for several days following release, suggesting that the first few days after release may be a recovery period in response to capture, handling, and tagging (Matthews, 1990a). The effects of tagging and handling on blue rockfish are difficult to determine. All fish were held in the laboratory from 1-7 days where the effects of bladder inflation, tagging, and handling could be assessed. Matthews and Reavis (1989) suggested that fish were stressed by capture and handling. As a result, fish released at the surface may be eaten before they reached the bottom. Researchers, therefore, may overestimate the probability of resighting a tagged fish without an accurate estimate of survivorship. Cass et al. (1990) described lingcod, Ophiodon elongatus, as a voracious predator of fishes and invertebrates, with many species of fishes, including rockfishes, found in their 
stomachs. Two tagged fish returned by sport divers during this study were eaten by lingcod. I also observed harbor seals, Phoca vitulina, feeding on rockfish in the gill nets during capture procedures.

Use of other survey techniques including telemetric studies can provide information concerning daily, weekly, and even seasonal movement patterns which can greatly enhance our knowledge of behavioral patterns in fishes. Telemetric studies by Matthews (1990a) suggested homing in copper and quillback rockfishes consisted of an initial orientation, use of olfaction or navigation to select a direction home, and recognition of familiar landmarks at the home site. If olfaction or visual recognition of familiar landmarks is used in homing, a directed, timely return to home sites should occur. Blue rockfish in this study were observed to have homed from various distances in different amounts of time. However, most fish which homed from $1.2 \mathrm{~km}$ took only one hour. Blue rockfish in this study may be familiar with certain landmarks within the cove (reefs, rock outcroppings) that may enable them to visually navigate when returning over short distances. Fish that were displaced farther away from their home site (unfamiliar with their surroundings) will presumably take longer returning to their home site, if they return at all.

Tag-recapture studies can allow for large number of fishes to be tagged and released over large areas and often rely on commercial and recreational fishermen for returns or resightings. One disadvantage tag-recapture studies have is the difficulty of making conclusions about behavioral patterns such as seasonal movement based on low recapture rates (3-10\%). Results from these recaptures may indicate one sort of behavior (e.g. sedentary, mobile), while the other $90-97 \%$ of unobserved fish may act very different. 
Another alternative to tag-recapture methods is visual resighting of tagged individuals using SCUBA. This method has the advantage of allowing assessment of in situ behavior. However, tagging-recapture techniques have limited success when used on mobile fishes with larger home ranges (Matthews and Reavis, 1989). Moreover, this method is only effective during day surveys, and has limited use during periods of strong currents and swell. In this study, surveys were done only during the day. Observation of fish behavior from these surveys may be biased in giving an indication that fish do not move, when in fact they may move frequently and at night. Also, surveys were only done when weather patterns allowed for safe launching and retrieval of the skiff. Blue rockfish may move between reefs or offshore during adverse conditions such as increased swell and winter storms.

In this study I assumed the location of capture was the home site and that fish did not distribute themselves randomly after release. Additionally, I assumed that fish that homed successfully did so by a directed path rather than by chance. It is possible that fish were not at their home site when captured and moved to their home sites following release or displacement. This would affect resighting proportions as well as increase the amount of straying between and away from reefs. Based on four of eight fish returning from Arrowhead Point in spring 1989,1 expected at least $50 \%$ of the fish would home from $(1.2 \mathrm{~km})$. Only $18 \%$ (9 of 50) were observed to home from Arrowhead Point during fall in 1990 and $3 \%$ (9 of 150) in spring 1991.

If fish collected were not residents of Wash Rock, then fish should have been distributed randomly throughout the cove. The remaining $80-90 \%$ of the unreported tagged individuals could have died, been eaten, or relocated to 
other reefs within or outside of Stillwater Cove. Moreover, there was a bias in the effort used to resight tagged fish at each site (Table 4). It is possible that fish remained at release sites and were not resighted because I did fewer surveys at these sites. However, no tagged fish were ever resighted at any location other than at the capture or release site during random surveys throughout Stillwater cove. Although only two or three surveys were done during spring 1991 at offshore pinnacles west of Stillwater Cove, no tagged fish were ever resighted at these areas.

\section{Role of Olfaction}

In this study, I assumed that if olfaction was used in homing of blue rockfish, there was at least one detectable chemical cue at the home site. Hasler and Wisby (1951) speculated that olfaction was used by salmon when homing, and that successful return required streams to have persistent and perceptible odors. These odors allowed fishes to identify different streams, and retain a memory of the home stream during periods of upstream migrations. Electroencephalographic studies of salmon olfactory nerves indicated successful recognition of home stream water (Hara, 1970).

Pigeons have homing abilities similar to migrant fishes. Pigeons have returned $1500 \mathrm{~km}$ to their home loft in a times which preclude random searching. Anosmic pigeons are far less successful in homing, i.e. they take longer and more fail to home than untreated controls. Treated (anosmic) birds also return home more effectively from familiar sites than unfamiliar sites, indicating olfactory deprivation does not eliminate homing behavior, and visual cues can provide sufficient information (Stoddart, 1980). Anosmic blue rockfish 
returned to their home site from distances of up to $2.6 \mathrm{~km}$, but were not observed to have returned from $4.4 \mathrm{~km}$. It may be that the successful anosmic fish returned using some other sensory mechanism, such as vision, or that they returned by random chance. However, SCUBA surveys conducted randomly in the vicinity of the release sites indicated no tagged individuals relocated to reefs adjacent to these release sites.

Tagging experiments with anosmic fish are complicated by the lack of knowledge about behavioral side effects. If the operation eliminates homing, the question still remains whether this result is due to behavioral side effects or to interference with chemical sensitivity. These complications can be reduced when treated fish can be shown to have completed behavioral functions such as upstream movement, reproduction, or feeding behavior without being influenced by normal, untreated fish (Stasko, 1971). Peters (1971) argued that nose-plugged fishes may home with less precision because of traumatic or inhibitory effects rather than because of olfactory loss. Consequently, sensoryimpairment experiments are only limited evidence for the olfactory hypothesis.

Because extensive handling and impairment procedures may change the natural behavior of blue rockfish, individuals were observed ieeding in the laboratory. No mortality occurred in the laboratory among anosmic fish, and no differences in feeding behavior were seen between them and normal fish. Olfactory impairment did not influence feeding behavior in longear sunfish, Lepomis megaloptis megalotis; however, movement patterns were affected, suggesting olfaction mediates homing in this species (Gunning, 1959). Because no behavioral differences were found in the laboratory between normal and anosmic fish, I suggest that impairment procedures used in this 
study did not influence the natural behavior of fish in the field experiment.

Although specific sensory impairment does not alter homing and orientation ability of the subject, it may result in increased mortality by predation, or alter the behavior of the subject in such a way as to make it less likely to be resighted even though it is in the home site. Resighting of anosmic fish following replacement at their home site did not differ significantly from resighting of normal fish (Fig. 9). Geoff and Green (1978) suggested in order to properly address the role of olfaction in homing, it is first necessary to determine the likelihood of resighting normal and anosmic fishes at their home site (transplant controls). Geoff and Green (1978) concluded anosmic stichaeids resighted at their home site after displacement of $19 \mathrm{~m}$ may not have been completely anosmized.

Chemical emissions from conspecifics may influence a wide variety of social interactions including general social attraction (perhaps for schooling), territorial marking, species, sex, and individual recognition, courtship, the induction of physiological readiness for mating, and in parent-young interactions (Liley, 1982). Local movements of some species of Pacific salmon are not strongly influenced by siblings or other conspecifics (Brannon and Quinn, 1990). Clear evidence exists that courtship in fish leading to fertilization depends to some extent upon the production of odors either by the male, female, or both. While mating is seldom eliminated by loss of olfactory power, it can be seriously impaired (Stoddart, 1980). Plugging the nostrils of male Bathygobius resulted in elimination of courtship behavior, indicating the importance of olfaction and odor cues for individual recognition (Stoddart, 1980). I observed some blue rockfish rubbing up against conspecifics in large 
aggregations after being released. Recognition of individuals at the home site may be done using olfaction and species-specific chemical scents. If fish released to different sites do not recognize other conspecifics, either by olfaction or vision, they may be more likely to return to their home site.

Artificial displacement studies of newts and frogs illustrate some problems involved with assessing the importance of one sensory system in an integrated control system. Although the olfactory system of frogs has been shown to play a role in homing, field studies using anosmic individuals have failed to demonstrate total elimination of homing behavior. This failure emphasizes complexity of the sensory control mechanisms in behaviors which return animals to their home sites or breeding grounds (Stoddart, 1980). If an experimentally blinded animal finds its way home, the experimenter did not demonstrate that this animal did not use visual cues: rather he has demonstrated that it was able to gather enough information to get home without visual cues. Blue rockfish in this study may have utilized more than one sensory mechanism when returning after being displaced. Olfaction and vision may be beneficial for increasing the success of homing, but may not be essential for returning. Additionally, one or both of these senses may be used in recognizing the home site after homing from release sites.

L'abee-Lund and Vøllestad (1985) hypothesized that environmental instability or unpredictability would reduce the benefits accrued by homing and hence reduce the proportion of fishes in a population that home. Environmental variability in rivers is greater in spring than fall, which may explain greater homing success in fall spawning salmon than spring (Quinn and Tallman, 1987). Also, salmon may locate large rivers more frequently than small ones 
because large rivers may be more predictable from generation to generation and may contain more persistent scents (Quinn and Tallman, 1987). If certain areas of Stillwater Cove, such as Wash Rock, are more stable in the amount of kelp canopy that persists over winter, and in the availability of food, then it may be more beneficial to occupy Wash Rock during these times and utilize this area as a home site. During this study, tagged fish were never seen during any season at any reef other than Wash Rock. Additionally, abundances of blue rockfish at this location remain relatively constant during all seasons. If this site is a more suitable and stable habitat over time than any other reef in the cove, then the benefits must be great in returning to this location after being experimentally displaced.

As suggested by Miller et al. (1967), my results indicate home site fidelity and narrow home ranges in blue rockfish. Since these fish comprise a significant part of the recreational fishery in California, they thus have the potential of being overexploited due to their resident nature. Miller et al. (1967) also concluded that blue rockfish move on average less than one mile. I found that even though fish were always resighted at their home site and never seen more than 20-25 $\mathrm{m}$ from their capture location, some fish were not seen for up to one year following initial resighting, and then resighted again at their home site. This suggests that fish may move to other locations at different times of the year, possibly offshore during winter. This may also be indirect evidence for increased movement patterns in this species.

All data analyzed using chi-square methods in this study have certain limitations. Due to low sample sizes, many of the comparisons that were made are biased. According to Zar (1984) if the expected values are small, the 
calculated $X^{2}$ is biased because it can be larger than the the theoretical $X^{2}$ is supposed to estimate. Also, expected values may not be representative. Significant results (Table 3 ) should not be taken as conclusive evidence and their limitations, due to low sample sizes, should be noted.

In the present study, the role of olfaction was assessed using anosmic individuals. Both normal and anosmic fish were able to home; however, normal fish were statistically more successful. Laboratory and field observations of both normal and anosmic fish indicate impairment and handling procedures did not affect the natural behavior of this species. Thus, while olfaction may play a role in blue rockfish homing behavior, information necessary for more successful homing performance is probably received from many senses which together far exceed the capacity of any single sense.

In summary, tag returns from various displacement sites demonstrated that homing ability in this species was reduced with increasing distance displaced. Fish were able to return from distances of up to $5 \mathrm{~km}$, but this occurred less frequently than in fish displaced shorter distances. Fish were also more successful at returning in summer and fall versus winter and spring. These differences are thought to be due to environmental stability and persistence of kelp canopy. All sizes of fish in this study were able to home. Both small and large fish were resighted during all sampling periods; however, larger fish tended to return to their home sites after the first 100 days. Differences in homing success in this study was found between males and females after 40 days, with only females being resighted. Transplant controls suggested that males were more often resighted at Wash Rock than females in the early part of the study, but both were resighted in similar proportion later in 
the study.

Further studies addressing sensory involvement in homing are needed to help identify mechanisms utilized during returns from experimental or natural displacements. Utilization of alternate tagging techniques such as telemetry may prove useful in determining the role of certain sensory mechanisms in homing and provide valuable information concerning directional components of homing. These methods may also help us to understand additional behavioral patterns that tag-recapture techniques do not such as time required to return certain distances from release sites. 


\section{LITERATURE CITED}

Bodkin, J.L. 1986. Fish Assemblages in Macrocystis and Nereocystis Kelp Forests Off Central California. Fish. Bull: 84(4) 799-808.

1988. Effects of kelp forest removal on associated fish assemblages in central California. J. Exp. Mar. Biol. Ecol., Vol. 117:227-238.

Bodkin, J.L., G.R. VanBlaricom, and R.J. Jameson. 1987. Mortalities of kelp-forest fishes associated with large oceanic waves off central California, 1982-1983. Envir. Biol. Fishes 18(1): 73-76.

Brannon, E.L. and T.P. Quinn. 1990. Field test of the pheromone hypothesis for homing by pacific salmon. J. Chem. Ecol. 16(2):603-609.

Brown, C.J.D. 1962. Olfactory apparatus in the black rockfish, Sebastodes melanops. Copeia, 4: 838-840.

Carlson, H. R. and R.E. Haight. 1972. Evidence for a Home Site and Homing of Adult Yellowtail Rockfish, Sebastes flavidus. J. Fish. Res. Board Can: 29(7) 1011-1014.

Cass, A.J., R.J. Beamish, and G.A. McFarlane. 1990. Lincod (Ophiodon elongatus). Can J.Fish. Aquat. Sci. Spec. Publ. 109: 40pp.

Craik, G.J.S. 1981. The effect of age and length on homing performance in the intertidal cottid, Oligocottus maculosus. Can. J. Zool., 59: 598-604.

Culver, B.N. 1986. Results from tagging black rockfish (Sebastes melanops) off the Washington and northern Oregon coast. Proc. Int. Rockfish Symp., Anchorage, Alaska: 231-239.

Dingle, Hugh. 1985. Migration and life histories. Pgs. 27-42. In Mary Ann Rankin, editor. Migration: mechanisms and adaptive significance. Univ. of Texas Suppl. Vol.27. Port Aransas, Texas.Migration: Mechanisms and Adaptive Significance Volume 27.

Eschmeyer, W.N. and E.S. Herald. 1983. Pacific Coast Fishes. Houghton Mifflin Co., Boston: 336pp.

Gerking, S.D. 1959. The restricted movement of fish populations. Biol. Rev. 34(2): 221-242.

Gibbs, M.A. 1991. Sexual dimorphism in the olfactory organs of some deepsea fishes. Masters Thesis. Moss Landing Marine Laboratories, Moss Landing, CA. 
Goff, G.P. and J.M. Green. 1978. Field studies on the sensory basis of homing and orientation to the home site in Ulvaria subbifurcata (Pisces: Stichaeidae). Can. J. Zool. 56: 2220-2224.

Green, J.M. 1971. High tide movements and homing behavior of the tidepool sculpin Oligocottus maculosus. J. Fish. Res. Bd. Can., 28: 383-389.

Green, J.M. 1973. Evidence for homing in mosshead sculpin (Clinocottus globiceps). J. Fish. Res. Bd. Canada 30: 129-130.

Groves, A.B., G.B. Collins, and P.S. Trefethen. 1967. Roles of olfaction and vision in choice of spawning site by homing adult chinook salmon (Oncorhynchus tshawytscha). J. Res. Bd. Canada 25(5): 867-876.

Gunning, G.E. 1959. The sensory basis for homing in the longear sunfish, Lepomis megalotis megalotis (Rafinesque). Invest. Indiana Lakes and Streams, 5(3): 103-130.

Hallacher, L.E. 1984. Relocation of original territories by displaced black and yellow rockfish, Sebastes chrysomelas, from Carmel Bay, California. Calif. Fish Game 70: 158-162.

Hallacher, L.E., and Dale A. Roberts. 1985. Differential utilization of space and food by the inshore rockfishes (Scorpaenidae: Sebastes) of Carmel Bay, California. Envir. Biol. Fish.:12(2) 91-110.

Hara, T.J. and B. Zielinski. 1989. Structural and functional development of the olfactory organ in teleosts. Trans. Amer. Fish. Soc., 118: 183-194.

Hara, T.J., 1970. An Electrophysiological Basis for Olfacory Discrimination in Homing Salmon: A Review. J. Res. Board Can.: 27(3): 565-586.

Harden Jones, F.R. 1968. Fish Migrations. Edward Arnold, London. 325pp.

Hasler, A.D. and W.J. Wisby. 1951. Discrimination of stream odors by fishes and relation to parent stream behavior. Amer. Nat., 85: 223-238.

Hobson, E.S. and J.R. Chess. 1988. Trophic relations of the blue rockfish, Sebastes mystinus, in a coastal upwelling system off northern California. Fish. Bull., 86(4): 715-743.

Khoo, Hong Woo. 1974. Sensory basis for homing in the intertidal fish Oligocottus maculosus Girard. Can. Journ. Zoo.: vol. 52: 1023-1029. 
L'Abee-Lund, J.H. and L.A. Vøllestad. 1985. Homing precision of roach, Rutilus rutilus in Lake Arungen, Norway. Envir. Biol. Fishes 13(2): 235239.

LaBar, G.W. 1971. Movement and homing of cutthroat trout (Salmo clarki) in Clear and Bridge Creek, Yellowstone National Park. Trans. Amer. Fish. Soc. 1: 41-49.

Leggett, L.C. 1977. The ecology of fish migrations. Ann. Rev. Ecol. Syst., 8: 285-308.

Leggett, L.C. 1985. The role of migrations in the life history evolution of fish. Pgs. 277-295. In Mary Ann Rankin, editor. Migration: mechanisms and adaptive significance. Univ. of Texas Suppl. Vol.27. Port Aransas, Texas.

Lenarz, William H. 1986. A history of California rockfish fisheries. Proc. Int. Rockfish Symp. Alaska Sea Grant Report: 87(2) 35-41.

Lenarz, William H. and T.W. Echeverria. 1986. Comparison of visceral fat and gonadal fat volumes of yellowtail rockfish, Sebastes flavidus, during a normal year and a year of El Nino conditions. Fish. Bull. 84(3): 743-745.

Liley, N.R. 1982. Chemical communication in fish. Can. J. Fish. Aquat. Sci. 39:22-35.

Love, R.M. 1991. Probably more than you want to know about the fishes of the Pacific coast. Really Big Press, Santa Barbara, California, $215 p p$.

Markevich, A. I. 1988. Nature of territories and homing in the eastern sea-perch, Sebastes taczanowski. Journ. Ichthyol.: 28: 161-163.

Matthews, K.R. 1986. Movement of two nearshore, terretorial rockfishes previously reported as non-movers and implications for management. Calif. Fish and Game 72(2): 103-109.

Matthews, K.R. 1990a. A telemetric study of the home ranges and homing routes of copper and quillback rockfishes on shallow rocky reefs. Can. J. Zool., 68: 2243-2250.

1990b. An experimental study of the habitat preferences and movement patterns of copper, quillback, and brown rockfishes (Sebastes spp.). Envir. Biol. Fish., 29: 168-178. 
Matthews, K.R., and R.H.. Reavis. 1989. Underwater tagging and visual recapture as a technique for studying movement patterns of rockfish. Amer. Fish. Soc. Symp., 7: 168-172.

McCleave, J.D. 1967. Homing and orientation of cutthroat trout (Salmo clarki) in Yellowstone Lake, with special reference to olfaction and vision. J. Fish. Res. Bd. Can. 24(10): 2011-2044.

McCleave, J.D., G.P. Arnold, J.J. Dobson and W.H. Neill (editors). 1984. Mechanisms of Migration in Fishes. Plenum Press, New York.

Miller, D.J. and J.J. Geibel. 1973. Summary of blue rockfish and lingcod life histories; a reef ecology study; and giant kelp, Macrocystis pyrifera, experiments in Monterey Bay, California. California Department of Fish and Game 158: 137pp.

Miller, D.J., M.W. Odemar, and D.W. Gotshall. 1967. Life history and catch analysis of the blue rockfish (Sebastodes mystinus) off central California, 1961-1965. California Department of Fish and Game, MRO reference No. $67-14: 130 \mathrm{pp}$.

Miller, D.L., and R.N. Lea. 1972. Guide to coastal marine fishes of California. Calif. Fish Game, Fish. Bull. 157: 235p.

Miller, M.L. and B.W. Menzel. 1986. Movements, homing, and home range of muskellunge, Esox masquinongy, in West Okoboji Lake, lowa. Envir. Biol. Fish. 16(4): 243-255.

Northcote, T.G. 1978. Migratory strategies and production in freshwater fishes. Pp. 326-359. in Ecology of Freshwater Fish Production. S.D. Gerking (editor). Blackwell Scientific, Oxford, England.

Peters, Michael. 1971. Sensory mechanisms of homing in salmonids: A comment. Behavior 39(1): 18-19.

Quinn, T.P., 1990. Current controversies in the study of salmon homing. Ethology Ecol. Evol. 2: 49-63.

Quinn, T.P. and R.F. Tallman. 1987. Seasonal environmental predictability and homing in riverine fishes. Envir. Biol. Fish. 18(2): 155-159.

Reed, D.C. and M.S. Foster. 1984. The effects of canopy shading on algal recruitment and growth in a giant kelp forest. Ecology 65: 937-948.

Stasko, A.B. 1971. Review of field studies on fish orientation. Ann. New York Acad. Sci. 188: 12-29. 
Stoddart, D.M. 1980. The ecology of vertebrate olfaction. Chapman and Hall Publ., London and New York. 240pp.

VanDykhuizen, Gilbert. 1983. Activity patterns and feeding chronology of the kelp rockfish, Sebastes atrovirens, in a central California kelp forest. Masters Thesis. Moss Landing Marine Laboratories. Moss Landing, CA. $61 \mathrm{pp}$.

Wheeler, J.P., and G.H. Winters. 1984. Homing of atlantic herring (Clupea harengus harengus) in Newfoundland waters as indicated by tagging data. Can. J. Fish. Aquat. Sci. 41: 108-117.

Williams, G.C. 1957. Homing behavior of California Rocky Shore Fishes. Univ. of Cal. Publ. pp. 249-281.

Zar, J.H. 1984. Biostatistical analysis. 2nd ed. Prentice-Hall, Inc., New Jersey. 620 pp. 


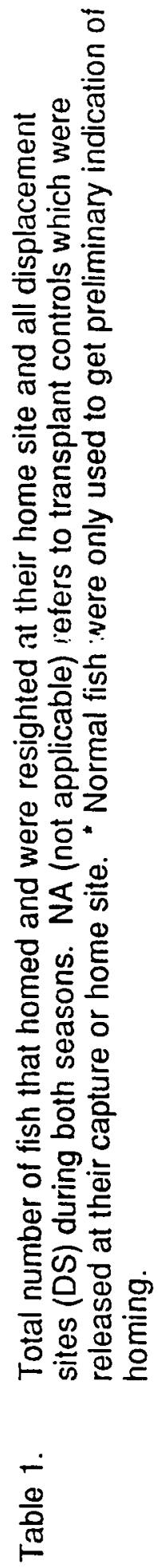

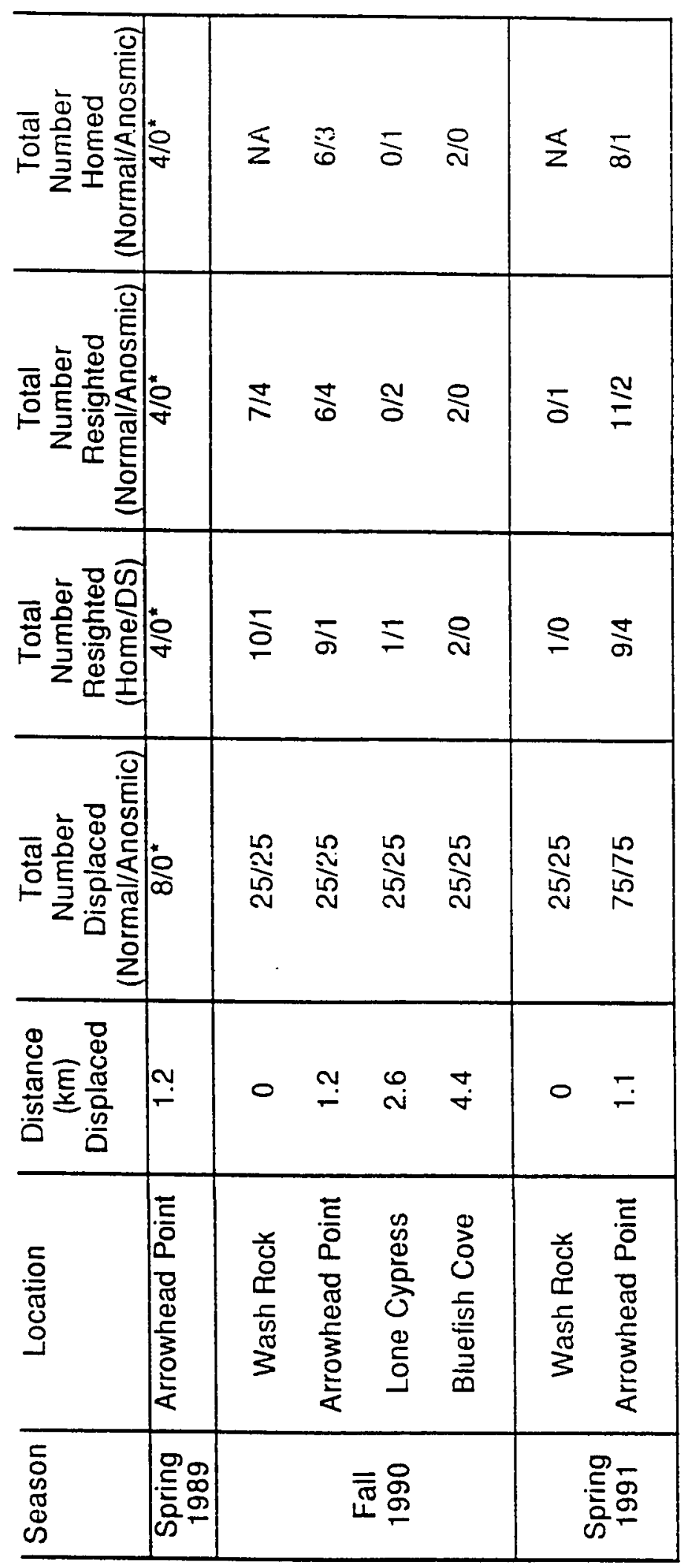


Table 2. Numer of normal and anosmic fish (by sex) which were captured and released following impairment procedures during both seasons.

\begin{tabular}{c|c|c|c} 
Season & Sex & $\begin{array}{c}\text { Number } \\
\text { Normal }\end{array}$ & $\begin{array}{c}\text { Number } \\
\text { Anosmic }\end{array}$ \\
\hline $\begin{array}{c}\text { Fall } \\
1990\end{array}$ & Male & 44 & 39 \\
& Female & 56 & 61 \\
$\begin{array}{c}\text { Spring } \\
\text { 1991 }\end{array}$ & Male & 43 & 46 \\
& Female & 54 & 57
\end{tabular}




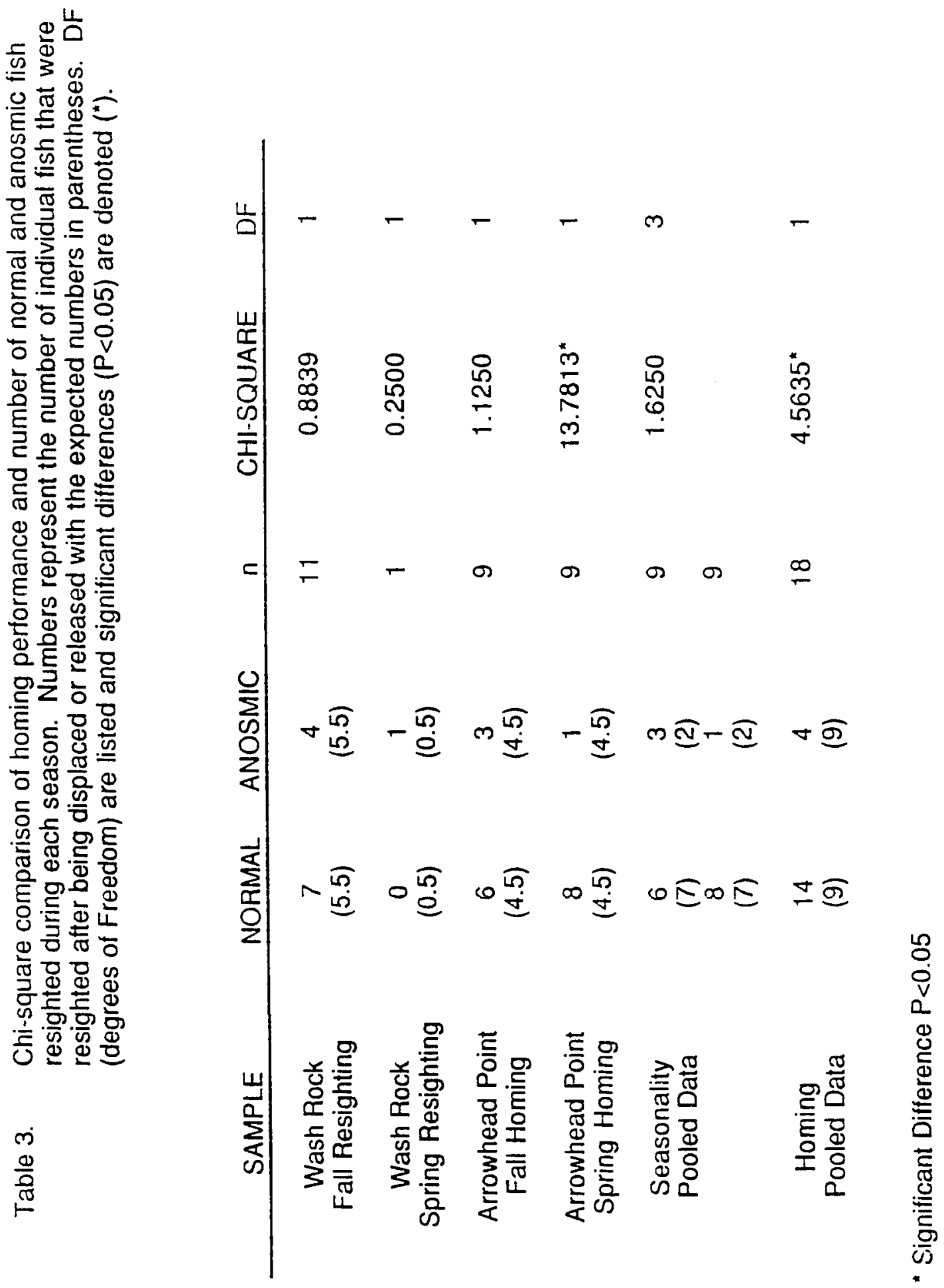


Table 4. Number of SCUBA surveys conducted at release sites during all seasons. Percent effort is the number of surveys at a particular site as a function of the total number of surveys done over that season.

\begin{tabular}{c|c|c|c} 
Season & Location & $\begin{array}{c}\text { Total } \\
\text { Number } \\
\text { Surveys }\end{array}$ & $\begin{array}{c}\text { Percent } \\
\text { Effort }\end{array}$ \\
\hline $\begin{array}{c}\text { Spring } \\
1989\end{array}$ & Wash Rock & 7 & 23 \\
& Arrowhead Point & 9 & 29 \\
& Pescadero Rocks & 7 & 23 \\
& Random & 8 & 25 \\
\hline \multirow{4}{*}{$\begin{array}{c}\text { Fall } \\
1990\end{array}$} & Wash Rock & 22 & 70 \\
& Arrowhead Point & 3 & 9 \\
& Bluefish Cove & 2 & 6 \\
& Random & 2 & 6 \\
\hline \multirow{3}{*}{$\begin{array}{c}\text { Spring } \\
1991\end{array}$} & Arrowhead Point & 5 & 13 \\
& Rash Rock & 26 & 67 \\
\hline
\end{tabular}


Figure 1. The location of the study sites in Carmel Bay, California. All displacement and release sites are denoted by solid squares ( $(\boldsymbol{)})$. 


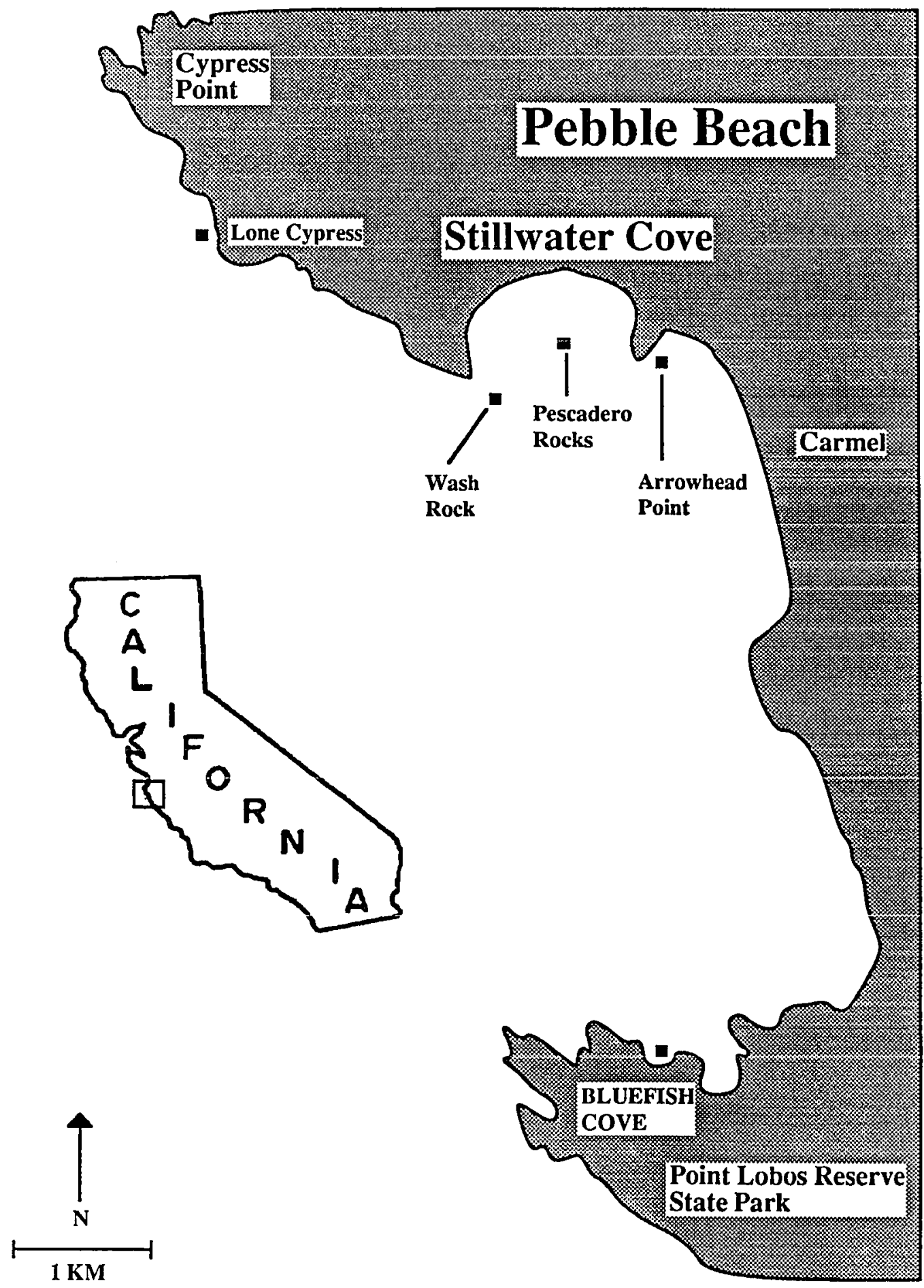


Figure 2. Head of a hypothetical bony fish; $A N=$ Anterior Naris, $P N=$ Posterior Naris. The skin between $A N$ and $P N$ are cut to expose the Nasal Rosette (R). Water flow across the Nasal Rosette is from anterior (Ant) to posterior (Post; From Gibbs, 1991). 

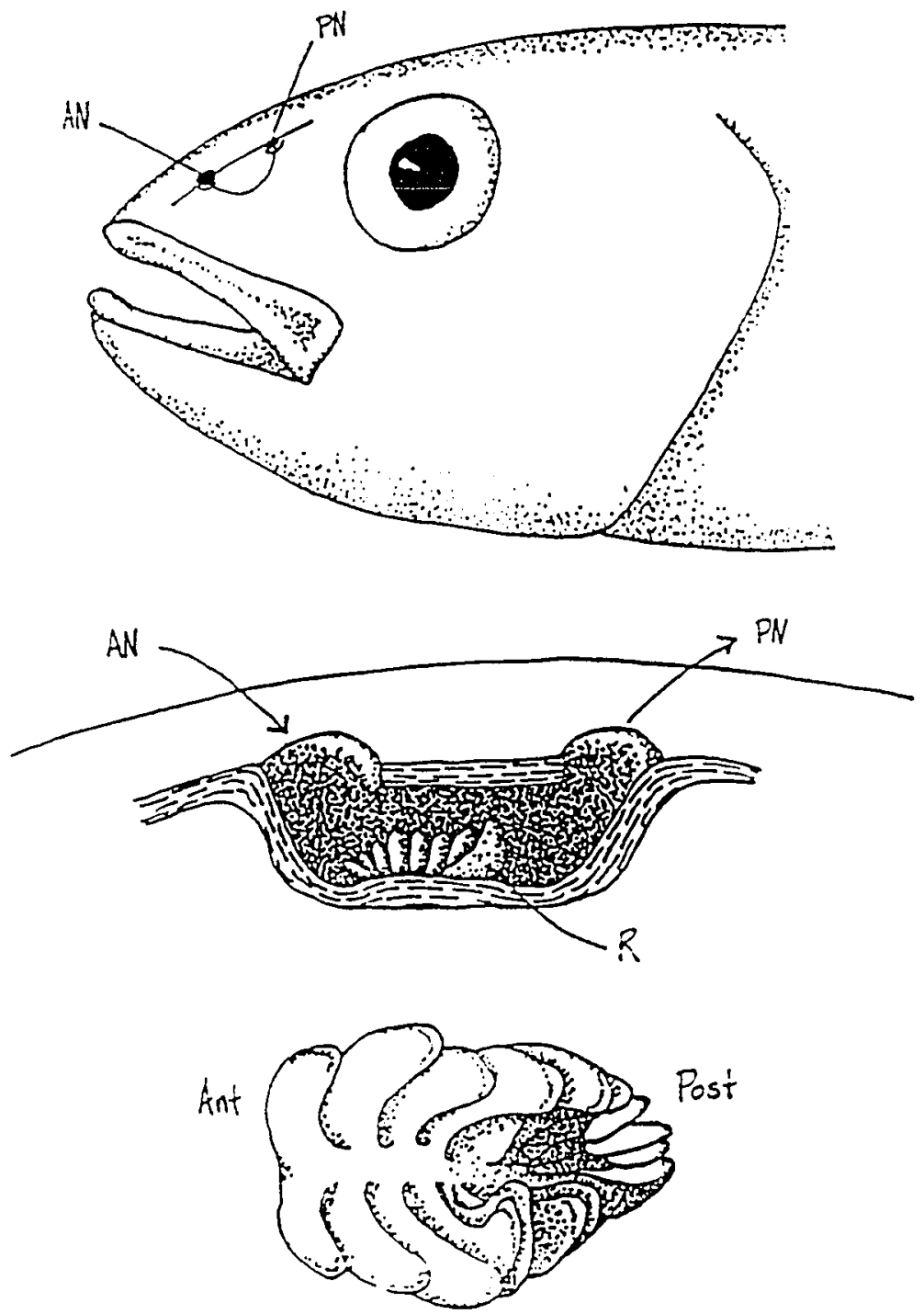
Figure 3. The relationship between the distance displaced and the number of days before an individual fish was resighted. Some fish were displaced between 1.2-4.4 $\mathrm{km}(\Delta)$, while others, used as transplant controls, were released at the capture or home site $(\bullet)$. 


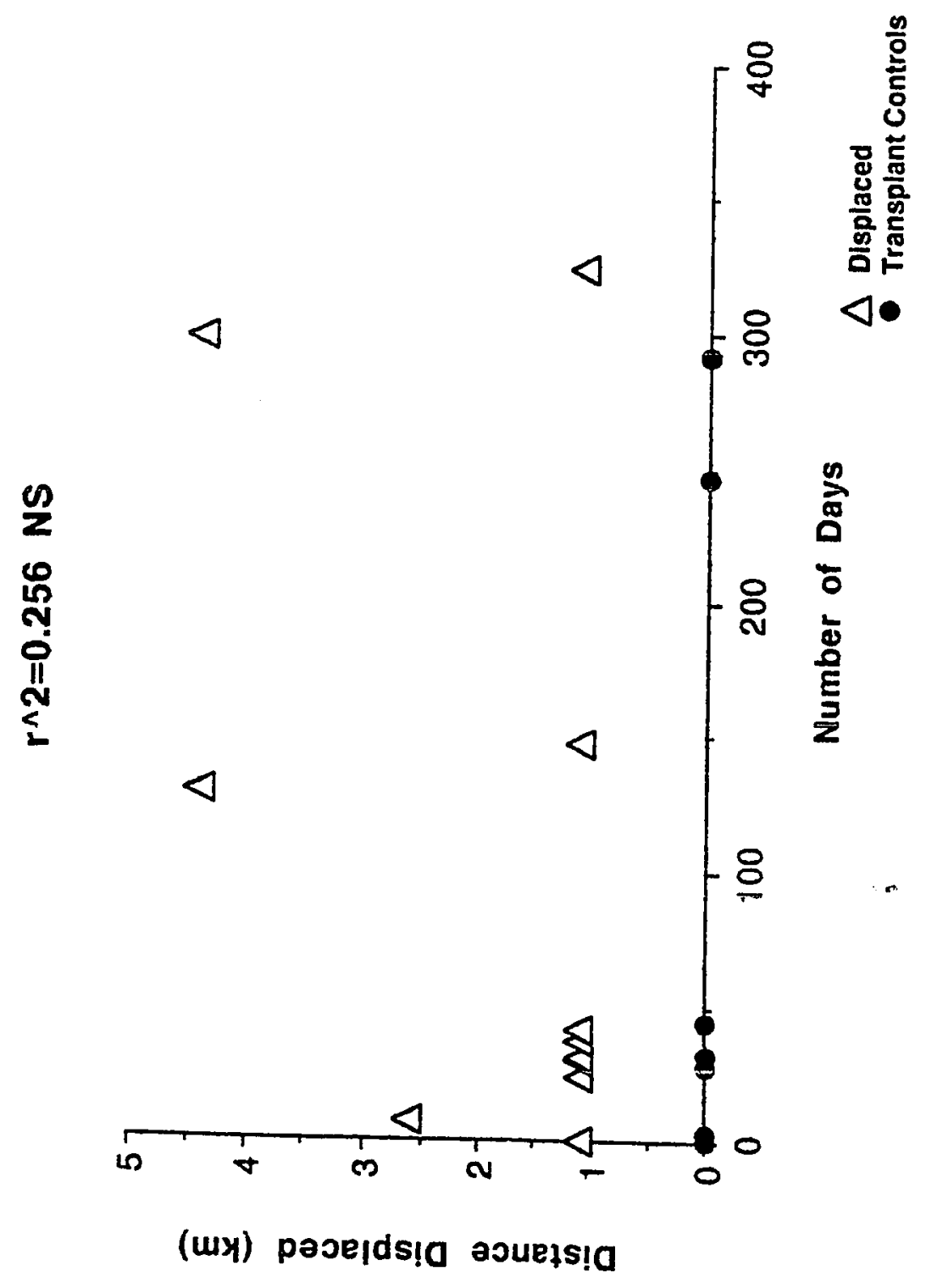


Figure 4. Size frequency distribution of fish captured, tagged, and released or displaced during both seasons. Size classes represent standard length in $\mathrm{mm}$. 


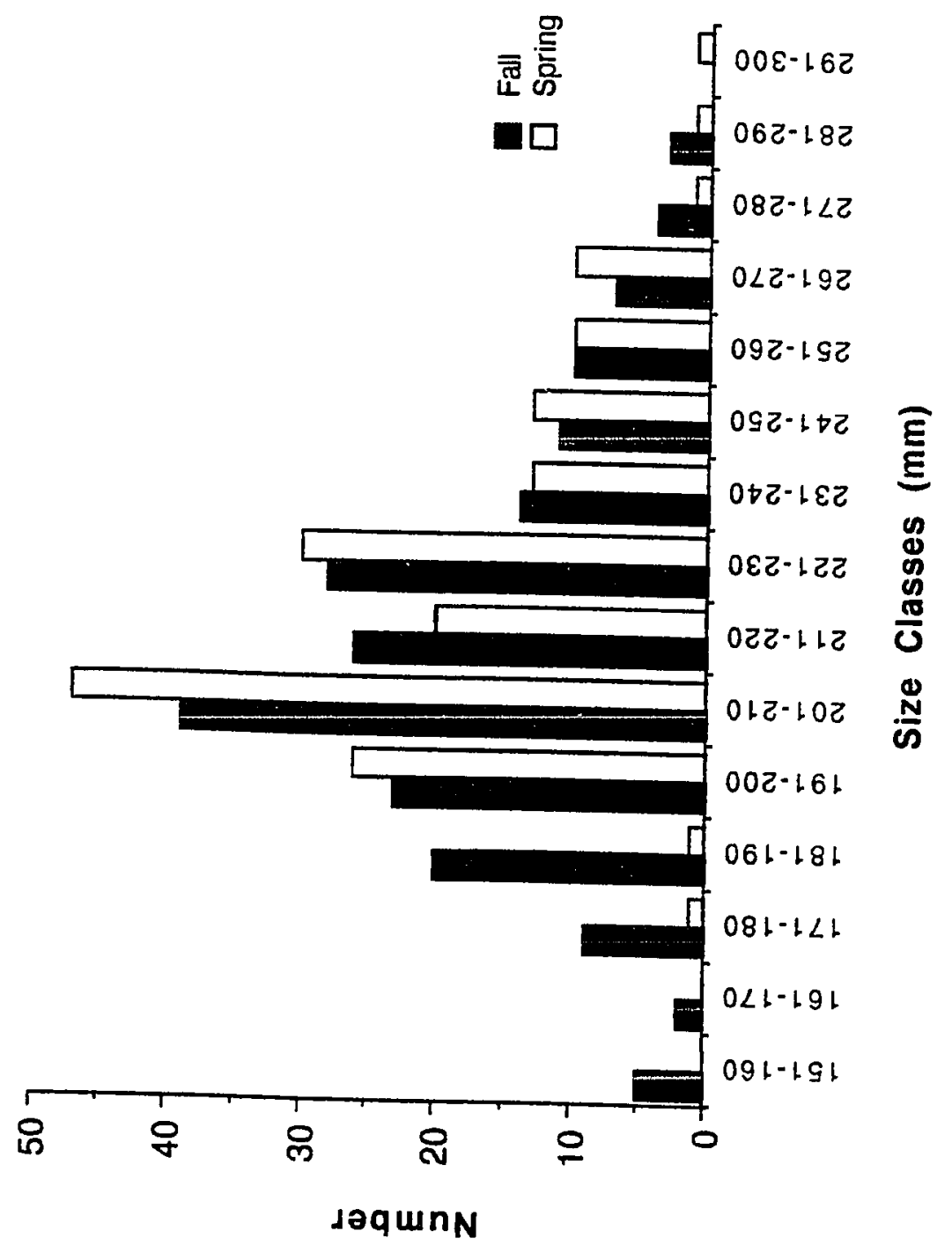


Figure 5. The relationship between size of fish (standard length in $\mathrm{mm}$ ) and the number of days before an individual fish was resighted for fish displaced between 1.2-4.4 km $(\Delta)$ and fish released at the capture site (transplant controls, $\bullet$ ) for both seasons combined. 


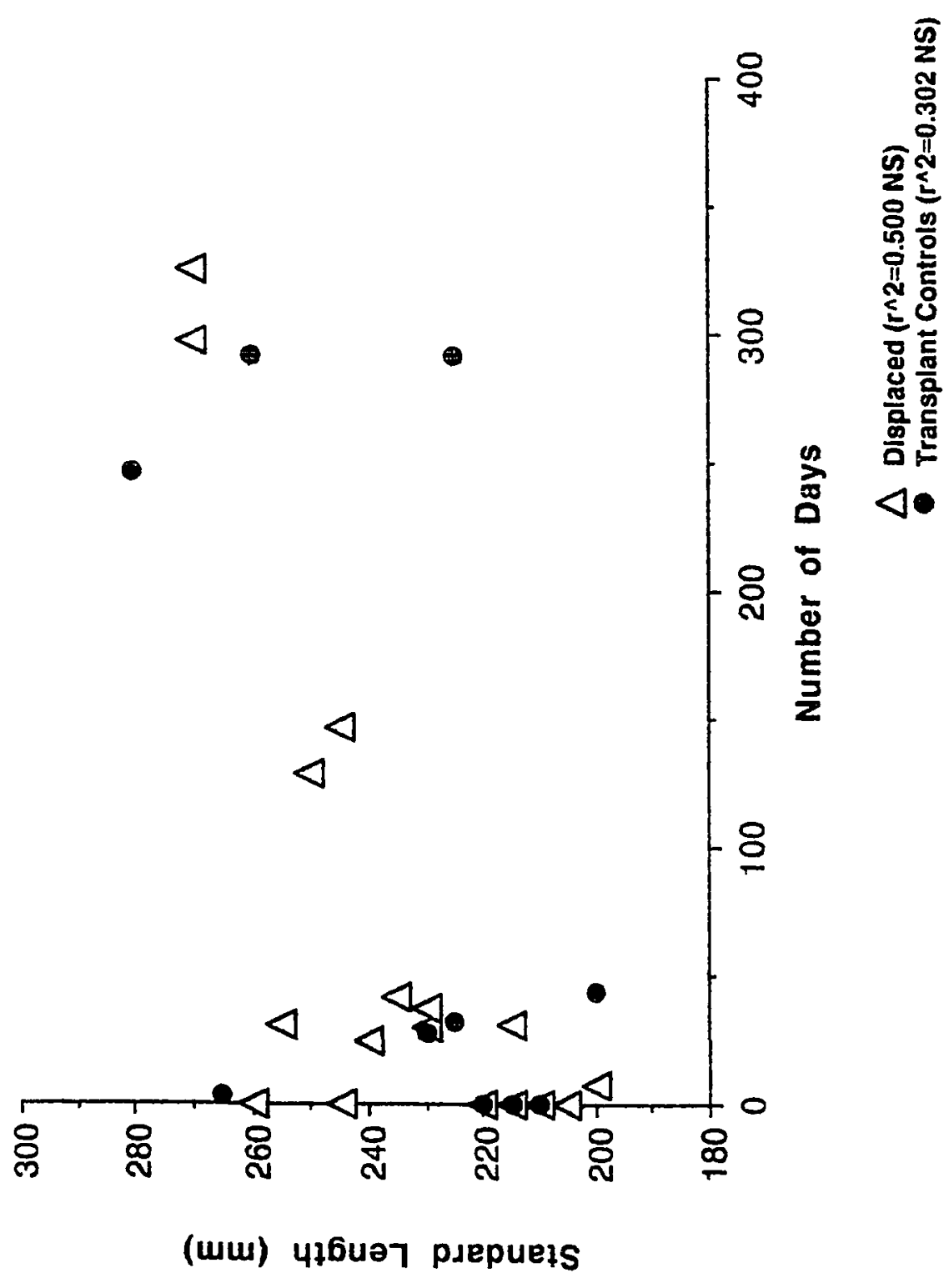


Figure 6. Relationship between the number of male and female fish which homed and were resighted (only once) and the number of days until they were resighted after being displaced between 1.2$4.4 \mathrm{~km}$. Horizontal bars represent duration of sampling periods for which SCUBA surveys were conducted. Fish ocurring outside sampling periods represent tag returns from divers and local fishermen. 


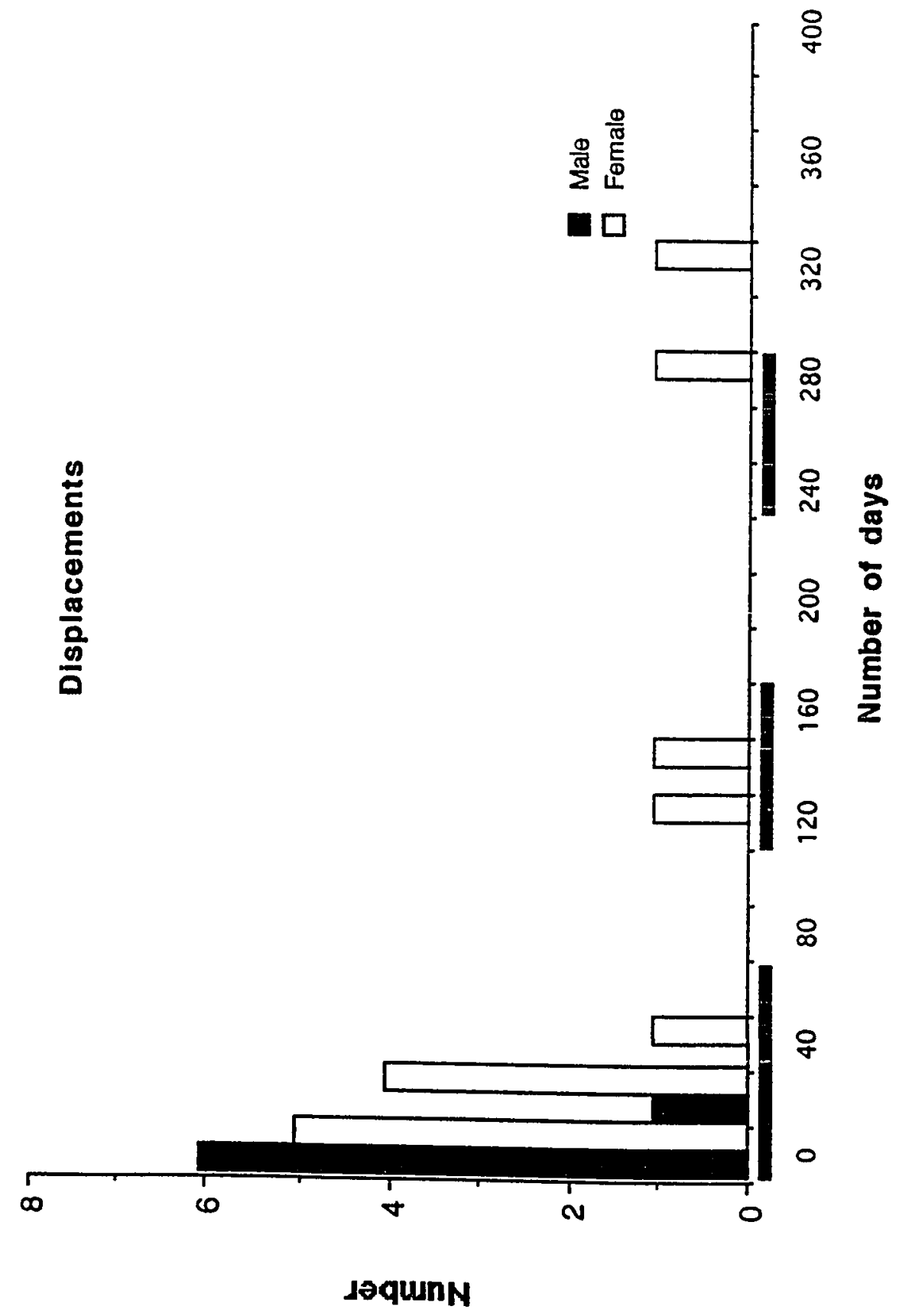


Figure 7. Relationship between the number of male and female fish which were resighted (only once) and the number of days until they were resighted a certain number of days after being released at the capture or home site (transplant controls). Horizontal bars represent duration of sampling periods for which SCUBA surveys were conducted. 


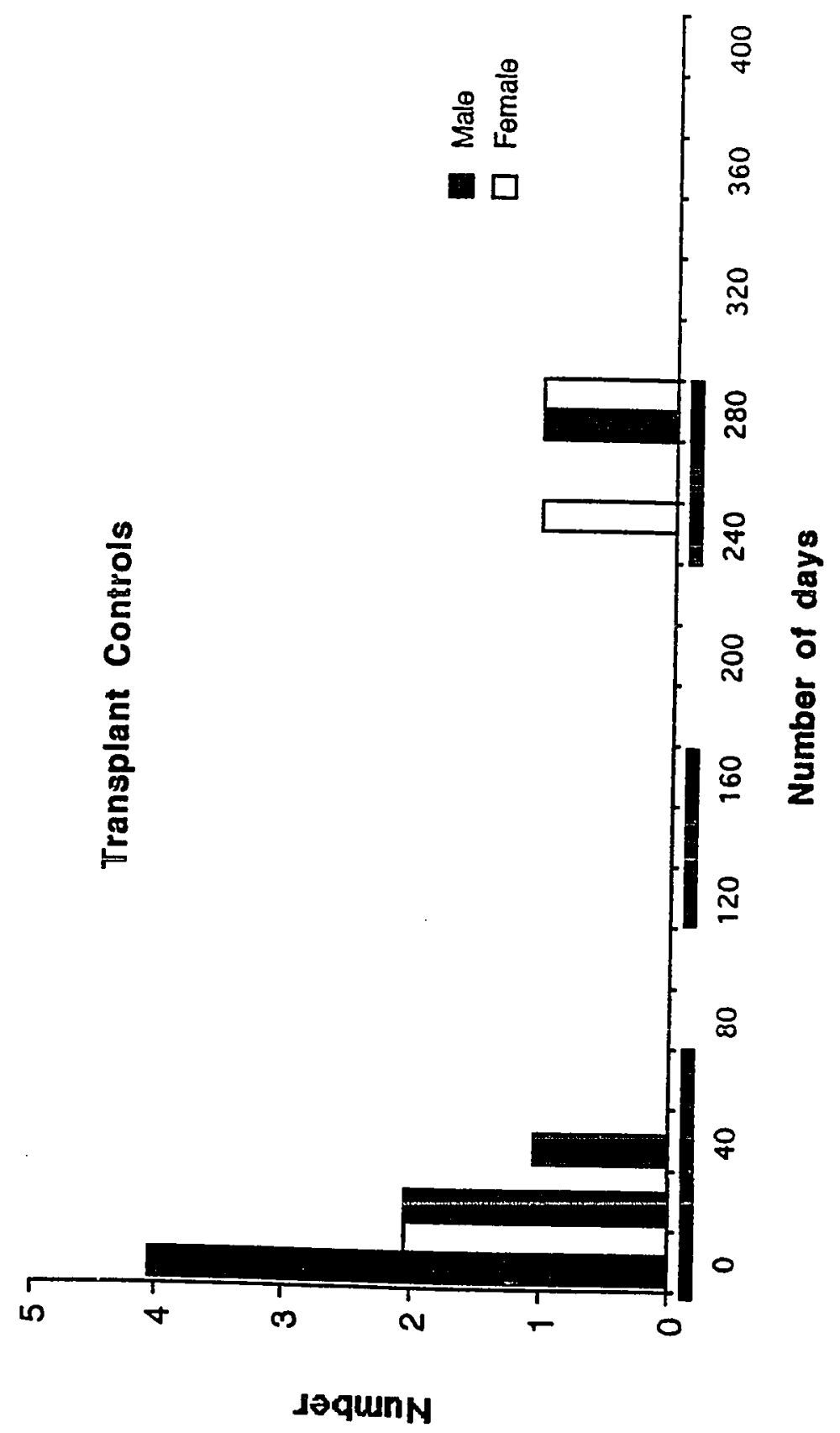


Figure 8. Relationship between the number of normal and anosmic fish which homed and were resighted (only once) and the number of days until they were resighted after being displaced between 1.2$4.4 \mathrm{~km}$. Horizontal bars represent duration of sampling periods for which SCUBA surveys were conducted. Fish ocurring outside sampling periods represent tag returns from divers and local fishermen. 


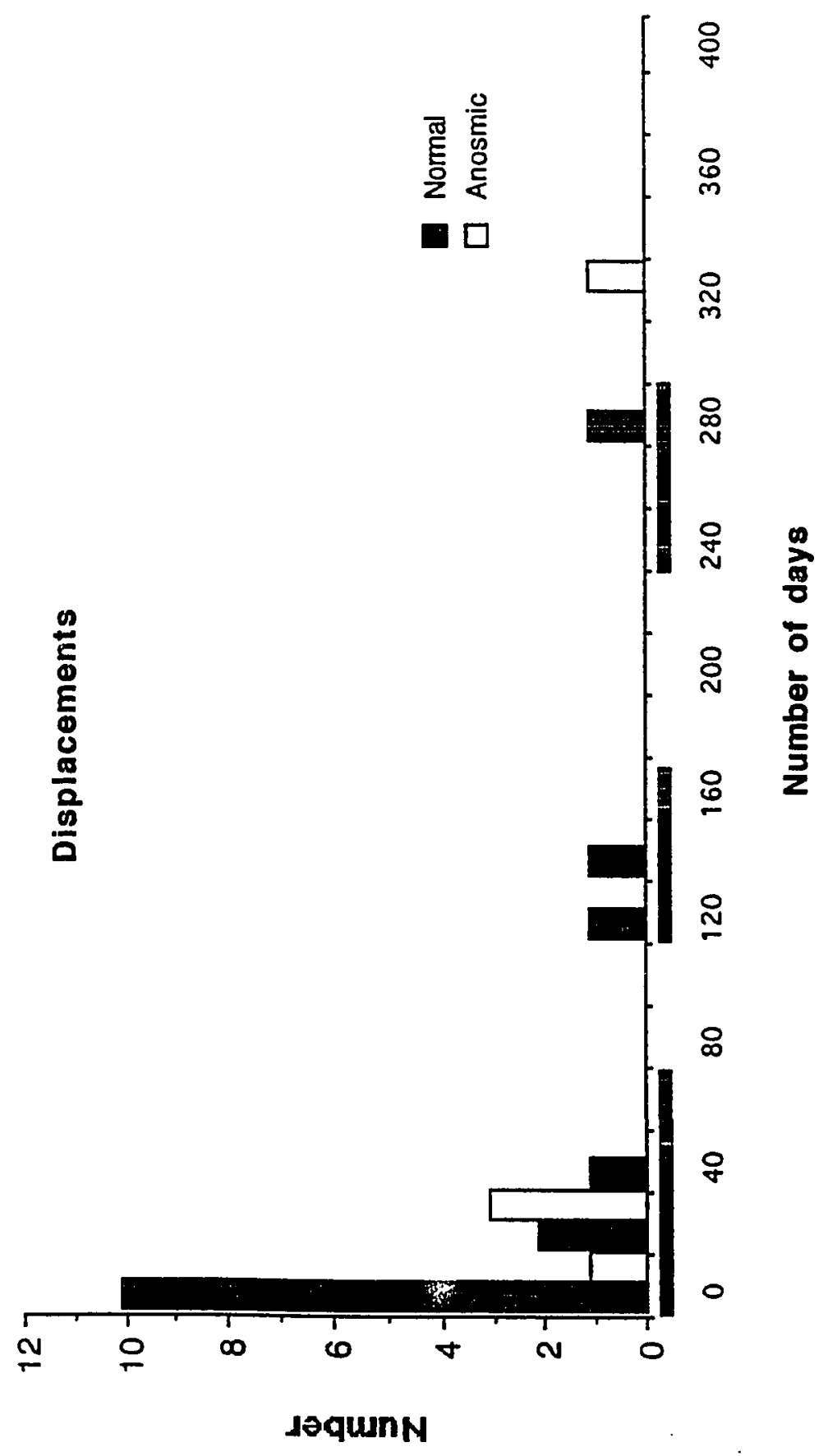


Figure 9. Relationship between the number of normal and anosmic fish resighted (only once) and the number of days until they were resighted after being released at the home or capture site(transplant controls). Horizontal bars represent duration of sampling periods for which SCUBA surveys were conducted. 


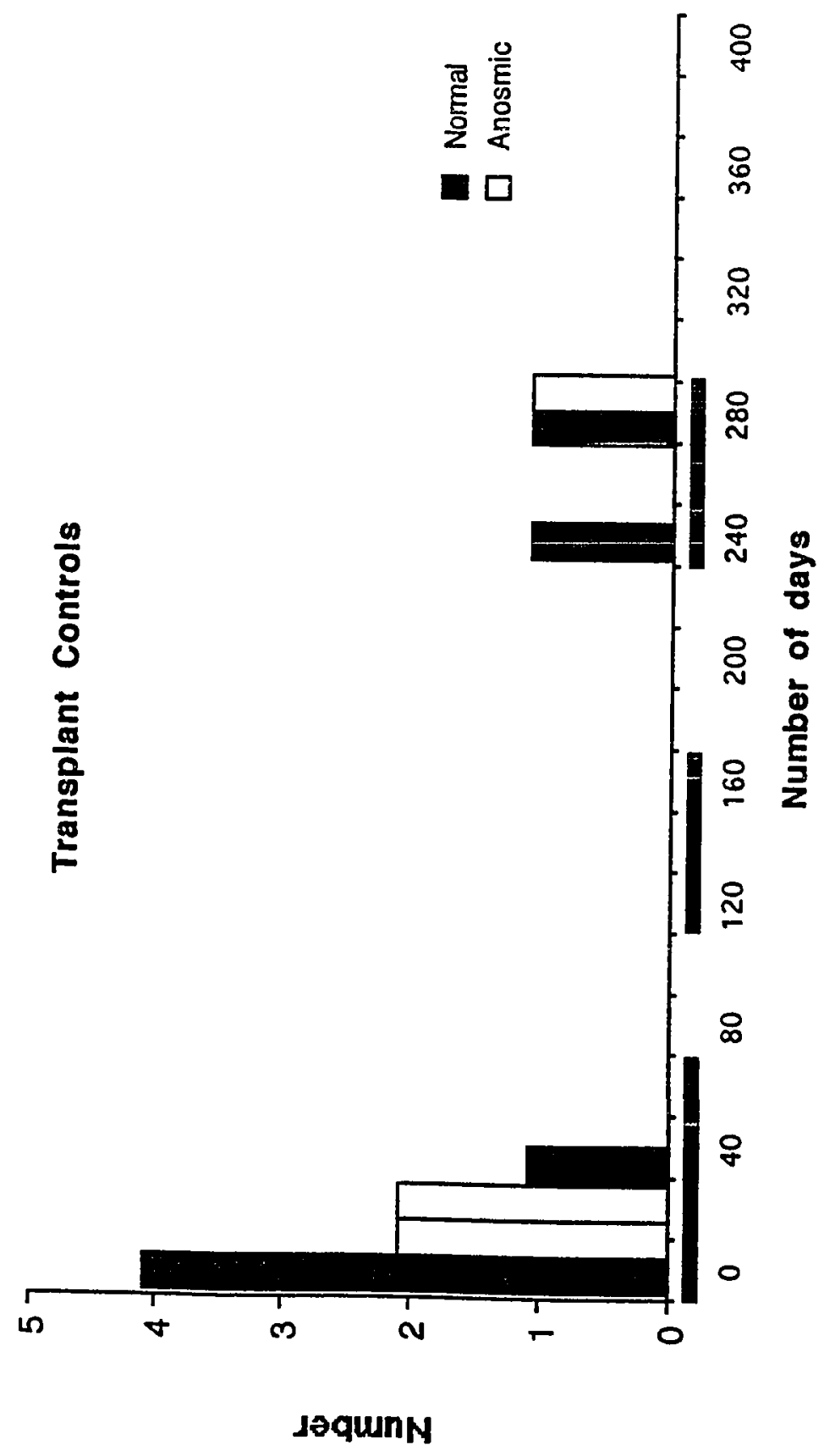


Figure 10a. Map showing the extent of giant kelp, Macrocystis pyrifera, within and outside of Stillwater Cove, Carmel, California during April in 1989. Dark areas represent kelp canopy and white areas are land and water. Study sites where fish were either displaced or released are indicated with arrows (From C. Harrold, Monterey Bay Aquarium). 


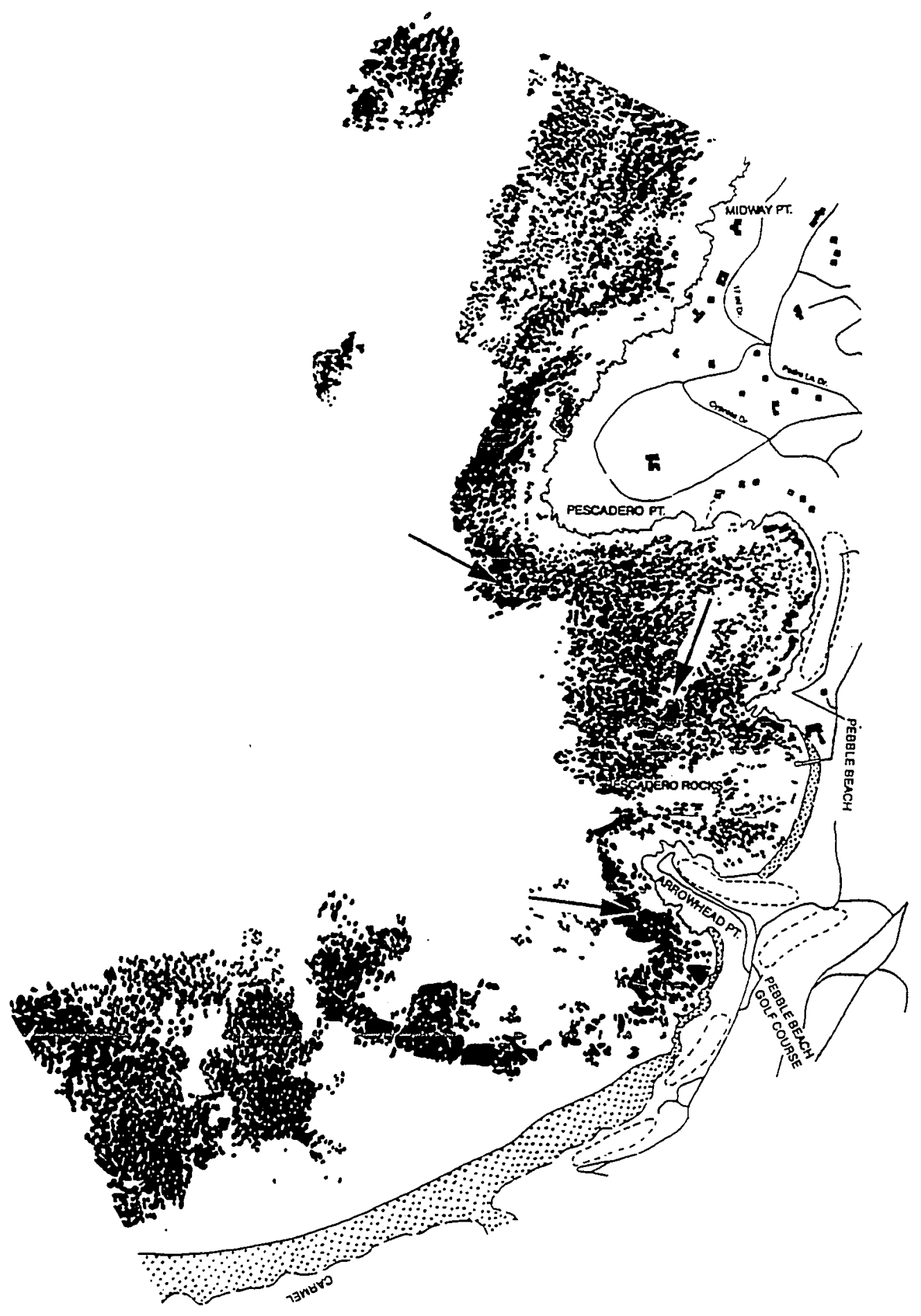


Figure 10b. Map showing the extent of giant kelp, Macrocystis pyrifera, within and outside of Stillwater Cove, Carmel, California during August in 1990. Dark areas represent kelp canopy and white areas are land and water. Study sites where fish were either displaced or released are indicated with arrows (From C. Harrold, Monterey Bay Aquarium). 


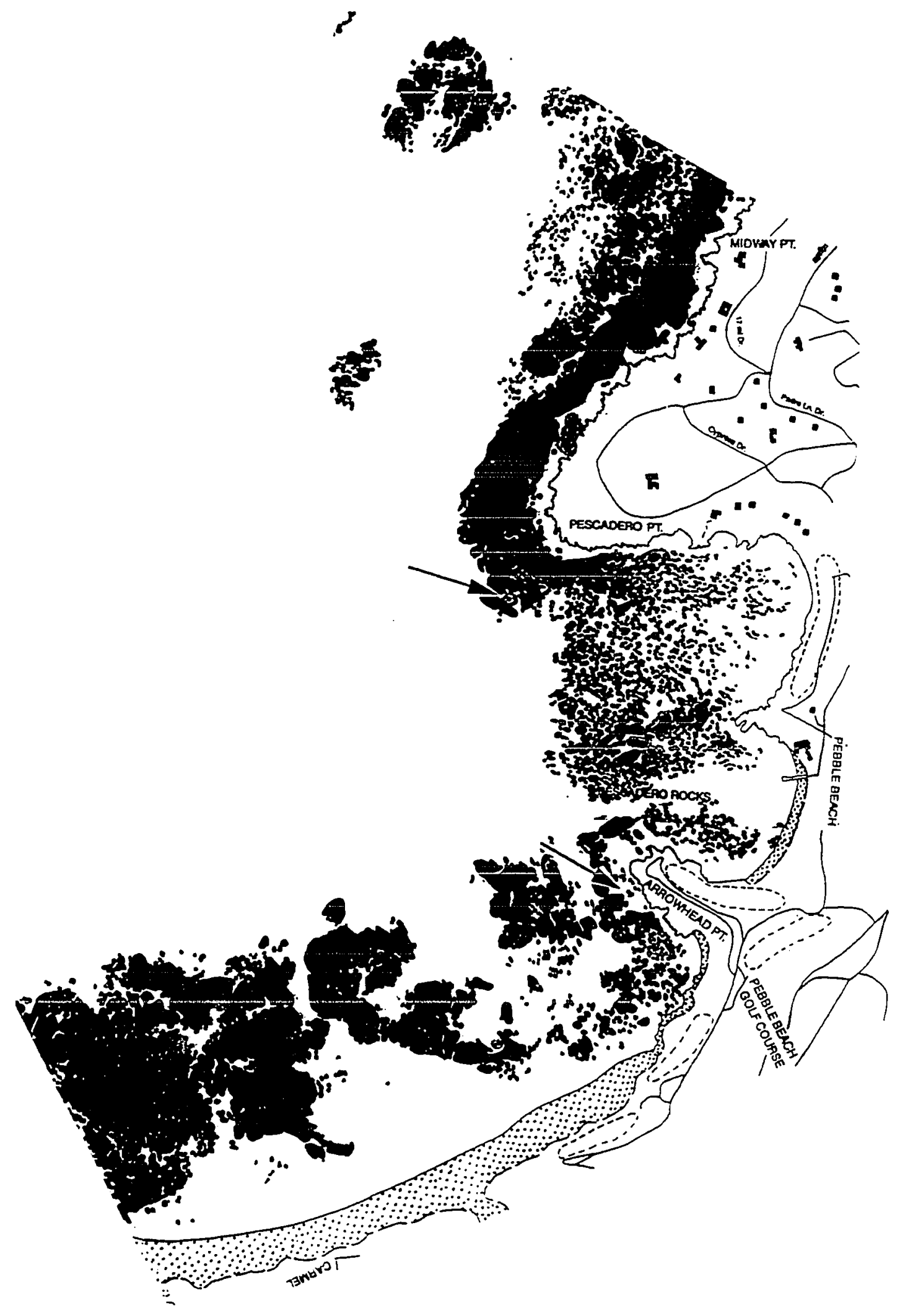


Figure 10c. Map showing the extent of giant kelp, Macrocystis pyrifera, within and outside of Stillwater Cove, Carmel, California during April in 1991. Dark areas represent kelp canopy and white areas are land and water. Study sites where fish were either displaced or released are indicated with arrows (From C. Harrold, Monterey Bay Aquarium). 


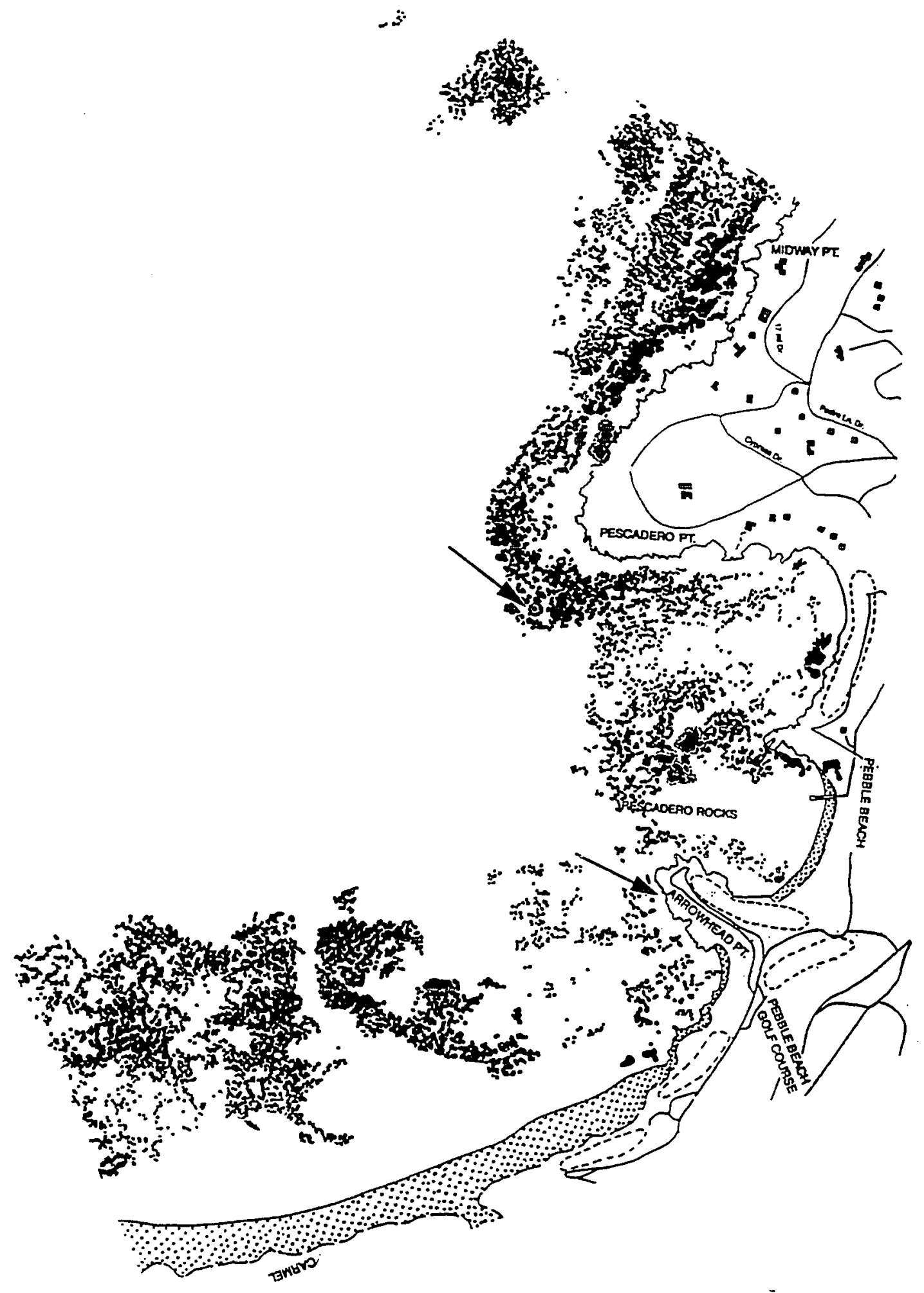

